\title{
Emerging Market Business Cycles: The Cycle is the Trend
}

\section{Citation}

Aguiar, Mark, and Gita Gopinath. 2007. Emerging market business cycles: The cycle is the trend. Journal of Political Economy 115(1): 69-102.

\section{Published Version}

http://dx.doi.org/10.1086/511283

\section{Permanent link}

http://nrs.harvard.edu/urn-3:HUL.InstRepos:11988098

\section{Terms of Use}

This article was downloaded from Harvard University's DASH repository, and is made available under the terms and conditions applicable to Other Posted Material, as set forth at http:// nrs.harvard.edu/urn-3:HUL.InstRepos:dash.current.terms-of-use\#LAA

\section{Share Your Story}

The Harvard community has made this article openly available.

Please share how this access benefits you. Submit a story.

Accessibility 


\title{
Emerging Market Business Cycles: The Cycle Is the Trend
}

\section{Mark Aguiar}

University of Rochester

\section{Gita Gopinath}

Harvard University and National Bureau of Economic Research

\begin{abstract}
Emerging market business cycles exhibit strongly countercyclical current accounts, consumption volatility that exceeds income volatility, and "sudden stops" in capital inflows. These features contrast with developed small open economies. Nevertheless, we show that a standard model characterizes both types of markets. Motivated by the frequent policy regime switches observed in emerging markets, our premise is that these economies are subject to substantial volatility in trend growth. Our methodology exploits the information in consumption and net exports to identify the persistence of productivity. We find that shocks to trend growth-rather than transitory fluctuations around a stable trend-are the primary source of fluctuations in emerging markets. The key features of emerging market business cycles are then shown to be consistent with this underlying income process in an otherwise standard equilibrium model.
\end{abstract}

\section{Introduction}

While business cycle fluctuations in developed markets may have moderated in recent decades (see Stock and Watson 2003), business cycles

We thank Seung Jung Lee for excellent research assistance. We thank Andy Atkeson, V. V. Chari, Steve Davis, Pierre-Olivier Gourinchas, Anil Kashyap, Patrick Kehoe, Ayhan Kose, and Fabrizio Perri for comments. We also thank workshop participants at a number of venues. We thank the Chicago Graduate School of Business for research support, and Gopinath thanks as well the James S. Kemper Foundation.

[Journal of Political Economy, 2007, vol. 115, no. 1]

(c) 2007 by The University of Chicago. All rights reserved. 0022-3808/2007/11501-0003 $\$ 10.00$ 
in emerging markets are characterized increasingly by their large volatility and dramatic current-account reversals, the so-called "sudden stop" phenomenon. The question we explore here is whether a standard real business cycle model can qualitatively and quantitatively explain business cycle features of both emerging and developed small open economies. Our underlying premise is that emerging markets, unlike developed markets, are characterized by frequent regime switches, a premise motivated by the dramatic reversals in fiscal, monetary, and trade policies observed in these economies. Consequently, shocks to trend growth are the primary source of fluctuations in these markets as opposed to transitory fluctuations around the trend. On the other hand, developed markets are characterized by a relatively stable trend. We show that this simple distinction takes us quite far in explaining differences in the two types of economies. In a standard framework with empirically estimated parameters, we generate strongly countercyclical current accounts, consumption volatility that exceeds income volatility, and sudden stops, all defining characteristics of emerging markets.

We begin by documenting in Section II several features of economic fluctuations in emerging and developed small open economies for the period 1980-2003. A striking feature that distinguishes the business cycles in the two is the strongly countercyclical nature of the trade balance for emerging markets as compared to developed markets. A second regularity is that consumption is 40 percent more volatile than income at business cycle frequencies for emerging markets, as compared to a ratio of little less than one for developed markets. In addition, income growth and net exports are twice as volatile in emerging markets.

Our hypothesis is that emerging markets are characterized by a volatile trend that determines the behavior of the economy at business cycle frequencies. More precisely, the relative importance of the random walk component of the Solow residual is larger in emerging markets. To test this hypothesis empirically, we need to distinguish transitory shocks from permanent shocks in the data. When we estimate the random walk component directly using empirical measures of the Solow residual, we find the results supportive of our premise. However, not surprisingly, given the short time series of the data, the results are sensitive to specification and imprecisely estimated. Extending the series back in time would not be particularly useful since it is only in the most recent decades that the phenomenon of "emerging-market economies" is observed. Specifically, many of our emerging-market economies were essentially closed economies during earlier periods and consequently displayed sharply different current-account dynamics. We therefore employ a methodology that uses the implications of a dynamic stochastic equilibrium model to precisely identify the underlying productivity parameters. 
In an environment in which agents have information regarding the persistence of the shock and respond in an optimizing manner, the behavior of macroeconomic aggregates such as consumption, investment, and net exports can be used to identify the parameters of the underlying productivity process. The direct approach using Solow residuals ignores this information. The intuition for our identification strategy follows from the permanent income hypothesis. The response of consumption to an income shock will differ according to the persistence of the shock. Suppose, for instance, that agents observe the economy entering a period of high growth. The fact that a shock to the growth rate implies a boost to current output, but an even larger boost to future output, implies that consumption responds more than income, reducing savings and generating a large trade deficit. Conversely, if the shock is transitory, agents will increase savings. Consumption accordingly will increase by less and the trade balance will deteriorate by a smaller amount. Therefore, if we observe in the data a large response of consumption to income and a corresponding large deterioration of net exports, the standard business cycle model will identify the underlying shock as a change in trend. If, however, for the same increase in output, consumption rises by less and net exports drop only slightly (or improve), the shock will be identified as a transitory shock. This methodology of combining consumption data with the permanent income hypothesis to identify the persistence of income shocks is similar to the approach in Campbell and Deaton (1989), Cochrane (1994), and Blundell and Preston (1998).

We demonstrate that this identification strategy can be used to precisely estimate the parameters of a productivity process that allows for both trend and transitory shocks. As our benchmark case, we use data from Mexico and Canada to represent emerging and developed markets respectively. Using data on consumption and income, we estimate the relative variance of the permanent component of productivity growth to total productivity growth to be 0.96 for Mexico and 0.37 for Canada. Similar estimates are obtained when using data on net exports rather than consumption. Using information from a wider set of moments generates essentially the same estimates as those obtained using only consumption or net exports. This underscores the fact that consumption is extremely informative regarding the persistence of income.

Moreover, the conclusions drawn from consumption are not contradicted by the information implicit in other moments. In particular, the theoretical business cycle moments on income, consumption, investment, and net exports, predicted using estimates of the productivity process for Mexico and Canada, match their empirical counterparts well. This is true even when we vary only two parameters-namely, the var- 
iances of trend and transitory shocks to productivity-between developed and emerging markets.

An additional test of consistency uses the empirical Solow residuals. The parameters of the productivity process were identified using the structural model and observed macroeconomic aggregates and were not estimated using direct measures of the Solow residual. Nevertheless, the variance and first eight autocovariances of the filtered Solow residual generated by the model are close to those found in the data. In particular, we cannot reject that the productivity moments of the model equal those in the data at standard confidence levels.

We also demonstrate that our model is consistent with the appearance of large current-account reversals or "sudden stops." We use the Kalman filter and the estimated parameters to decompose the observed Solow residual series for Mexico into trend and transitory components. When we feed the decomposed Solow residuals into the model, we generate a sharp sudden stop in 1994-95, including an abrupt and sizable reversal in the trade balance combined with contractions in output, consumption, and investment. The model predicts that the trade balance as a ratio of GDP should reverse by 8.2 percentage points between the third quarter of 1994 and the second quarter of 1995, which is similar to the 9.6-percentage-point reversal observed in the data. It is not just the magnitude of the shock, but additionally the association of the negative productivity shock with a change in trend, that lies behind the large sudden stop.

There exists a long and growing literature that seeks to explain the countercyclicality of current accounts and sudden stops in emerging markets. The international real business cycle literature showed early on that following a positive transitory shock to productivity, the trade balance can deteriorate even as savings rise because of the response of increased investment (Mendoza 1991; Backus, Kehoe, and Kydland 1995). Following the preceding discussion, the higher the persistence of the shock, the larger the trade balance deterioration. However, in the data, (Hodrick-Prescott-filtered) log GDP in emerging markets exhibits roughly the same autocorrelation as in developed small open economies. We show that this latter fact is not inconsistent with the hypothesis that emerging and developed markets face different combinations of trend and transitory shocks. This underscores how little information regarding persistence can be gleaned from the income process alone. Correspondingly, the standard model fails to quantitatively match the magnitude of the countercyclicality of the current account in emerging markets when calibrated as an AR(1) process using the observed autocorrelation of income (see Correia, Neves, and Rebelo 1995).

While we use a standard real business cycle model, we do not claim 
that market imperfections are unimportant. The differences in the Solow residual processes between developed and emerging markets may well be a manifestation of deeper frictions in the economy. Shocks to trend output in emerging markets are often associated with clearly defined changes in government policy, including dramatic changes in monetary, fiscal, and trade policies. ${ }^{1}$ Chari, Kehoe, and McGrattan (forthcoming), for instance, show that many frictions, including financial frictions, can be represented in reduced form as Solow residuals. From the perspective of private agents in our economy, these shocks appear as exogenous shifts in productivity. Our analysis provides support for models with frictions that are reflected in the persistence of Solow residuals rather than frictions that distort the response of investment and consumption to underlying productivity.

\section{Empirical Regularities of Emerging-Market Business Cycles}

In this section we document key aspects of small open economy business cycles with emphasis on the distinction between emerging and developed economies. The countries included in the analysis are listed in table 2 below. The sample consists of middle-income and developed economies that have at least 40 quarters of data. To focus on "small" economies, we exclude all Group of Seven countries other than Canada. This leaves us with 26 economies, 13 of which are classified as "emerging markets." We use the classification system used by Standard and Poor's (2000) and the International Finance Corporation to categorize a country as an emerging market. ${ }^{2}$ The Appendix provides details on the source of data for each economy in the sample.

Table 1 reports key moments of the business cycle averaged over emerging markets and developed economies, and table 2 contains a breakdown for each economy in our sample. After deseasonalizing the series when a significant seasonal component was discovered, ${ }^{3}$ we filtered the series to derive business cycle movements. We filtered each series using the Hodrick-Prescott filter with smoothing parameter 1,600 and verified our results using a band pass filter at frequencies between six and 32 quarters. The main conclusions are insensitive to the choice of filtering methodology, and we present details from the Hodrick-Prescott

\footnotetext{
${ }^{1}$ There is a large literature on the political economy of emerging markets in general, and the tensions behind the sporadic appearances of pro-growth regimes in particular, that supports our emphasis on trend volatility (see, e.g., Dornbusch and Edwards 1991).

${ }^{2}$ The two criteria used in defining a country as an emerging market are that (i) it is a low- or middle-income country as defined by the World Bank and (ii) its "investable" market capitalization is low relative to its most recent GNP figures. "Investable" is defined as the share of market capital that is accessible to foreign investors.

${ }^{3}$ Deseasonalization is performed using the Census Bureau's X-12 ARIMA program.
} 
TABLE 1

Emerging vs. Developed Markets (Averages)

\begin{tabular}{lcr}
\hline \hline & Emerging Markets & Developed Markets \\
\hline$\sigma(Y)$ & $2.74(.12)$ & $1.34(.05)$ \\
$\sigma(\Delta Y)$ & $1.87(.09)$ & $.95(.04)$ \\
$\rho(Y)$ & $.76(.02)$ & $.75(.03)$ \\
$\rho(\Delta Y)$ & $.23(.04)$ & $.09(.03)$ \\
$\sigma(C) / \sigma(Y)$ & $1.45(.02)$ & $.94(.04)$ \\
$\sigma(I) / \sigma(Y)$ & $3.91(.01)$ & $3.41(.01)$ \\
$\sigma(T B / Y)$ & $3.22(.17)$ & $1.02(.03)$ \\
$\rho(T B / Y, Y)$ & $-.51(.04)$ & $-.17(.04)$ \\
$\rho(C, Y)$ & $.72(.04)$ & $.66(.04)$ \\
$\rho(I, Y)$ & $.77(.04)$ & $.67(.04)$ \\
\hline
\end{tabular}

NotE. - This table lists average values of the moments for the group of emerging (13) and developed (13) economies. The values for each country separately are reported in table 2. Data are Hodrick-Prescott filtered using a smoothing parameter of 1,600. The standard deviations are in percentages. The standard errors for the averages were computed assuming independence across countries. The definition of an emerging market follows the classification in Standard \& Poor's (2000).

filtering exercise. ${ }^{4}$ Moments were calculated using generalized method of moments (GMM), and standard errors are reported in parentheses.

Panel A of table 2 reports the volatility and autocorrelation of filtered $\log$ output and the first difference of unfiltered log output. Emergingmarket economies on average have a business cycle twice as volatile as that of their developed counterparts. Column 2 reveals that this difference in volatility is also present in unfiltered first differences. Columns 3 and 4 document the first-order autocorrelation of filtered output and unfiltered output growth. Note that filtered output in emerging markets, on average, displays roughly the same autocorrelation as that of developed economies. Explanations of strongly countercyclical current accounts in emerging markets that rely on the relative persistence of shocks must confront this pattern as well.

Panel B of table 2 reports the volatility of filtered consumption, investment, and the ratio of net exports to GDP, expressed as a percentage of filtered output volatility. Unfortunately, because of data limitations, we are unable to analyze the behavior of hours worked over the business cycle. Perhaps the most striking fact of panel B is the volatility of consumption in emerging markets. At business cycle frequencies, consumption is roughly 40 percent more volatile than income in emerging markets. Conversely, in developed economies the ratio is slightly less than one on average. While individual economies show exceptions to

${ }^{4}$ One might question the use of the Hodrick-Prescott filter in a paper that stresses a stochastic trend. Of course, some detrending or normalization must be done to calculate unconditional moments of a nonstationary series. More important, we wish to replicate patterns that characterize the much-studied "business cycle frequencies," while highlighting the fact that the process that generates much of the variance at these frequencies also has a large low-frequency component. 
the average, the data suggest that emerging markets experience relatively volatile consumption at business cycle frequencies even when we control for the already high income volatility. There is a large literature on the excessive "smoothness" of consumption in the U.S. data (see, e.g., Campbell and Deaton 1989). Of course, whether consumption is excessively smooth in developed economies or excessively volatile in emerging markets depends on the underlying process for income. Once we parameterize and calibrate the income processes for developed and emerging markets in the next section, we can revisit the question of whether consumption is too volatile in emerging markets.

Panel C of table 2 documents the correlation of consumption, investment, and net exports with income at business cycle frequencies. A distinguishing feature of emerging-market business cycles is the large, negative correlation of net exports and output. The average correlation for emerging markets is -0.51 , with several countries approaching -0.8 . Conversely, developed economies exhibit weakly countercyclical trade balances, with an average correlation of -0.17 .

One concern with the empirical regularities documented in tables 1 and 2 is the measurement error associated with emerging-market data, particularly at the quarterly frequency. We calculated the same set of moments reported in table 1 using annual data over the same time frame and found that the patterns are robust to this particular concern. For both quarterly and annual data, we found that the 1980s and 1990s separately exhibited patterns similar to those observed from pooling both decades.

When we use annual data, for which a longer time series is available, we found that several of the distinguishing features of emerging-market business cycles documented using the more recent data are weaker or not present at all in the 1960s or 1970s. Specifically, the volatility of consumption is greater than that of income for the emerging-market group in both the pre- and post-1980 period. However, the negative correlation between the trade balance and GDP is larger for the developed sample $(-0.34)$ than for the emerging-market sample $(-0.18)$ in the pre-1980 period. This is reversed in the post-1980 period, for which the correlations are -0.32 and -0.54 , respectively. This lack of stationarity is perhaps to be expected given the dramatic transformation of these economies over the longer period. Specifically, many of our emerging-market economies were essentially closed economies or had tight controls on private capital flows during the earlier period. We therefore confine our analysis to the patterns observed over the last 20 years.

In the next sections, we provide a simple explanation for the observed differences between emerging- and developed-market fluctuations that relies on the differences in the underlying income process for these 
TABLE 2

A. Volatility and Autocorrelation of Filtered Income and Growth Rates

\begin{tabular}{lcccr}
\hline \hline & $\sigma(Y)$ & $\sigma(\Delta Y)$ & $\rho\left(Y_{t}, Y_{t-1}\right)$ & $\rho\left(\Delta Y_{t}, \Delta Y_{t-1}\right)$ \\
\hline Emerging markets: & & & & \\
$\quad$ Argentina & $3.68(.42)$ & $2.28(.37)$ & $.85(.02)$ & $.61(.08)$ \\
Brazil & $1.98(.20)$ & $1.69(.33)$ & $.65(.04)$ & $.35(.15)$ \\
Ecuador & $2.44(.52)$ & $1.52(.38)$ & $.82(.05)$ & $.15(.14)$ \\
Israel & $1.95(.14)$ & $1.99(.17)$ & $.50(.10)$ & $-.27(.05)$ \\
Korea & $2.51(.46)$ & $1.71(.27)$ & $.78(.08)$ & $.17(.19)$ \\
Malaysia & $3.10(.65)$ & $1.84(.37)$ & $.85(.02)$ & $.56(.16)$ \\
Mexico & $2.48(.33)$ & $1.53(.25)$ & $.82(.01)$ & $.27(.11)$ \\
Peru & $3.68(.70)$ & $2.97(.50)$ & $.64(.11)$ & $.12(.10)$ \\
Philippines & $3.00(.43)$ & $1.66(.27)$ & $.87(.07)$ & $.17(.15)$ \\
Slovak Republic & $1.24(.20)$ & $1.06(.24)$ & $.66(.18)$ & $-.20(.13)$ \\
South Africa & $1.62(.16)$ & $.85(.11)$ & $.88(.06)$ & $.53(.06)$ \\
Thailand & $4.35(.65)$ & $2.25(.40)$ & $.89(.02)$ & $.42(.20)$ \\
Turkey & $3.57(.41)$ & $2.92(.36)$ & $.67(.06)$ & $.05(.13)$ \\
Mean & 2.74 & 1.87 & .76 & .23 \\
Developed markets: & & & & \\
Australia & $1.39(.21)$ & $.84(.10)$ & $.84(.04)$ & $.36(.10)$ \\
Austria & $.89(.09)$ & $.55(.00)$ & $.85(.08)$ & $.52(.09)$ \\
Belgium & $1.02(.09)$ & $.71(.05)$ & $.79(.05)$ & $.18(.09)$ \\
Canada & $1.64(.21)$ & $.81(.09)$ & $.91(.04)$ & $.55(.11)$ \\
Denmark & $1.02(.16)$ & $1.04(.09)$ & $.49(.14)$ & $-.15(.11)$ \\
Finland & $2.18(.39)$ & $1.32(.11)$ & $.85(.09)$ & $.01(.20)$ \\
Netherlands & $1.20(.13)$ & $.88(.09)$ & $.77(.07)$ & $.03(.08)$ \\
New Zealand & $1.56(.20)$ & $1.13(.14)$ & $.77(.10)$ & $.02(.13)$ \\
Norway & $1.40(.10)$ & $1.46(.13)$ & $.48(.11)$ & $-.46(.10)$ \\
Portugal & $1.34(.14)$ & $1.03(.13)$ & $.72(.11)$ & $-.28(.17)$ \\
Spain & $1.11(.12)$ & $.75(.09)$ & $.82(.03)$ & $-.08(.18)$ \\
Sweden & $1.52(.20)$ & $1.45(.32)$ & $.53(.21)$ & $-.35(.11)$ \\
Switzerland & $1.11(.13)$ & $.50(.04)$ & $.92(.05)$ & $.81(.04)$ \\
Mean & 1.34 & .95 & .75 & .09 \\
\hline & & & \\
\hline
\end{tabular}

\begin{tabular}{lrll}
\hline \multicolumn{4}{c}{ B. Relative Volatility OF Consumption, Investment, AND Net ExpoRTs } \\
\hline \hline \multicolumn{5}{c}{$\sigma(C) / \sigma(Y)$} & $\sigma(I) / \sigma(Y)$ & $\sigma(\mathrm{NX} / Y)$ \\
\hline Emerging markets: & & & \\
$\quad$ Argentina & $1.38(.07)$ & $2.53(.01)$ & $2.56(.67)$ \\
Brazil & $2.01(.07)$ & $3.08(.03)$ & $2.61(.92)$ \\
Ecuador & $2.39(.01)$ & $5.56(.01)$ & $5.68(1.07)$ \\
Israel & $1.60(.00)$ & $3.42(.04)$ & $2.12(.18)$ \\
Korea & $1.23(.06)$ & $2.50(.04)$ & $2.32(.51)$ \\
Malaysia & $1.70(.03)$ & $4.82(.02)$ & $5.30(.77)$ \\
Mexico & $1.24(.05)$ & $4.05(.02)$ & $2.19(.32)$ \\
Peru & $.92(.08)$ & $2.37(.01)$ & $1.25(.15)$ \\
Philippines & $.62(.12)$ & $4.66(.02)$ & $3.21(.34)$ \\
Slovak Republic & $2.04(.08)$ & $7.77(.02)$ & $4.29(.56)$ \\
South Africa & $1.61(.08)$ & $3.87(.03)$ & $2.46(.50)$ \\
Thailand & $1.09(.07)$ & $3.49(.01)$ & $4.58(.85)$ \\
Turkey & $1.09(.06)$ & $2.71(.03)$ & $3.23(.40)$ \\
Mean & 1.45 & 3.91 & 3.22 \\
Developed markets: & & & \\
Australia & $.69(.00)$ & $3.69(.03)$ & $1.08(.12)$ \\
Austria & $.87(.14)$ & $2.75(.04)$ & $.65(.04)$ \\
Belgium & $.81(.13)$ & $3.72(.04)$ & $.91(.07)$ \\
Canada & $.77(.09)$ & $2.63(.03)$ & $.91(.08)$ \\
Denmark & $1.19(.10)$ & $3.90(.02)$ & $.88(.14)$ \\
& & 76 &
\end{tabular}


TABLE 2 (Continued)

\begin{tabular}{lrrr}
\hline \hline & $\sigma(C) / \sigma(Y)$ & $\sigma(I) / \sigma(Y)$ & $\sigma(\mathrm{NX} / Y)$ \\
\hline Finland & $.94(.07)$ & $3.26(.02)$ & $1.11(.10)$ \\
Netherlands & $1.07(.09)$ & $2.92(.03)$ & $.71(.09)$ \\
New Zealand & $.90(.10)$ & $4.38(.02)$ & $1.37(.18)$ \\
Norway & $1.32(.12)$ & $4.33(.03)$ & $1.73(.19)$ \\
Portugal & $1.02(.11)$ & $2.88(.05)$ & $1.16(.12)$ \\
Spain & $1.11(.07)$ & $3.70(.03)$ & $.86(.07)$ \\
Sweden & $.97(.14)$ & $3.66(.04)$ & $.94(.09)$ \\
Switzerland & $.51(.31)$ & $2.56(.05)$ & $.96(.09)$ \\
Mean & .94 & 3.41 & 1.02 \\
\hline \multicolumn{4}{c}{ C. ConTEMPORANEOUs CoRRELATION } \\
\hline \hline
\end{tabular}


countries. We argue that for emerging markets "the cycle is the trend." A well-recognized fact about emerging markets is that they experience fairly volatile cycles. A perhaps less appreciated fact is that emerging markets are subject to extremely volatile shocks to the stochastic trend. This paper argues that the relative importance of trend shocks distinguishes emerging markets from developed small open economies. In figure 1, we plot unfiltered annual log GDP per capita and log Solow residuals for two small open economies-Canada and Mexico. The data for the Solow residuals are taken from Bergoeing et al. (2002), which we extend through 2002; the details are described in the Appendix. Casual observation of the plots suggests that Canada, our benchmark developed small open economy, experiences small fluctuations around a relatively stable trend. On the other hand, Mexico displays a volatile trend with negative average growth in GDP per capita in the 1980s followed by slightly positive average growth in the 1990s. The Solow residual for Mexico similarly appears to have a more volatile trend. While this is suggestive, it is clearly not evidence that the stochastic trend is relatively more important for Mexico relative to Canada. To provide empirical support for this hypothesis, we need to distinguish transitory shocks from permanent shocks in the data. Our strategy is to use the implications of a dynamic stochastic equilibrium model to identify the underlying productivity parameters.

\section{Stochastic Growth Model}

The model is a standard, single-good, single-asset small open economy model augmented to include transitory and trend shocks to productivity. Specifically, technology is characterized by a Cobb-Douglas production function that uses capital, $K_{t}$, and labor, $L_{t}$, as inputs:

$$
Y_{t}=e^{z_{t}} K_{t}^{1-\alpha}\left(\Gamma_{t} L_{t}\right)^{\alpha}
$$

where $\alpha \in(0,1)$ represents labor's share of output. The parameters $z_{t}$ and $\Gamma_{t}$ represent productivity processes. The two productivity processes are characterized by different stochastic properties. Specifically, $z_{t}$ follows an $\mathrm{AR}(1)$ process

$$
z_{t}=\rho_{z} z_{t-1}+\epsilon_{t}^{z}
$$

with $\left|\rho_{z}\right|<1$, and $\epsilon_{t}^{z}$ represents independently and identically distributed draws from a normal distribution with zero mean and standard deviation $\sigma_{z^{*}}$ 

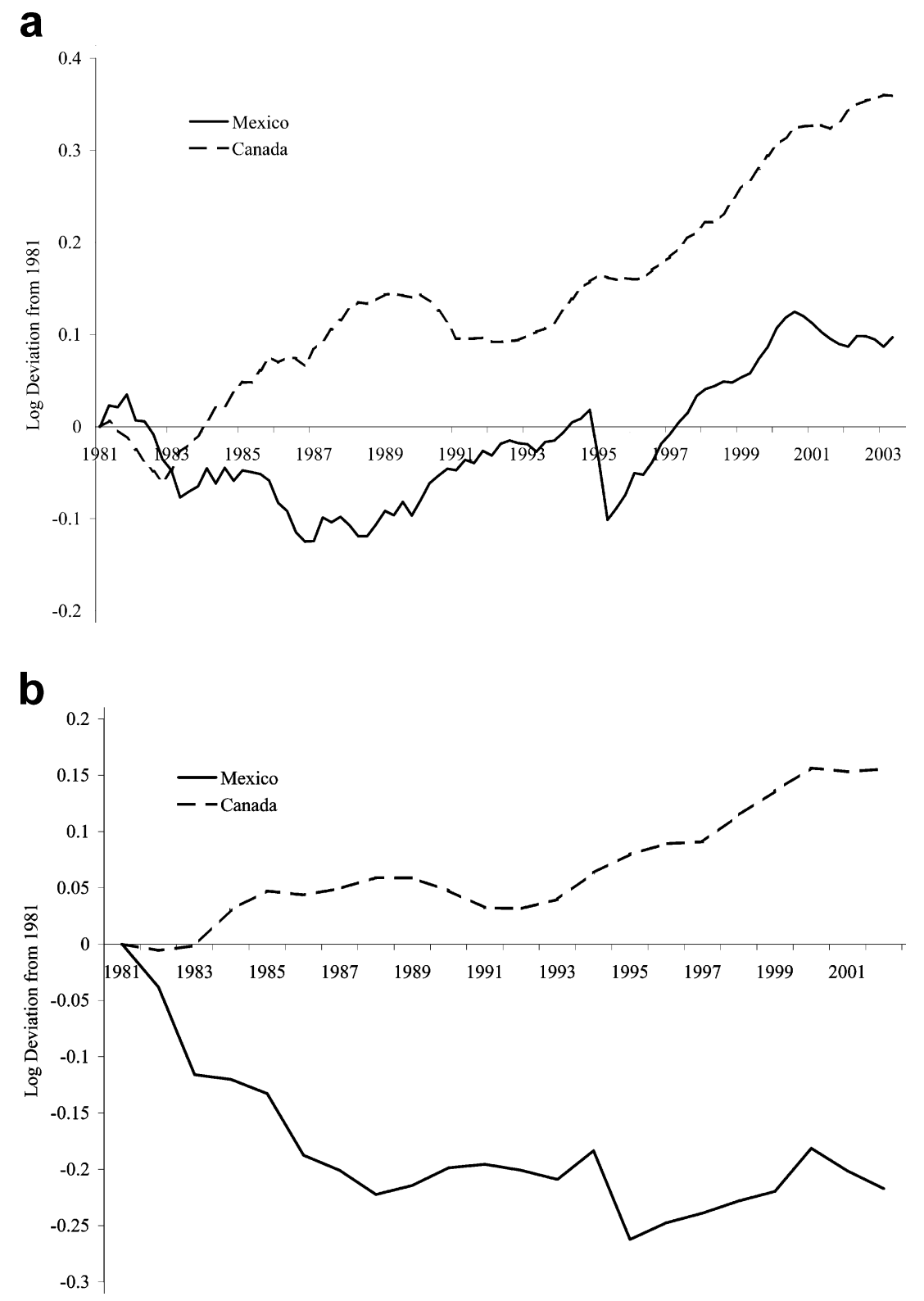

Fig. 1.-GDP per capita and Solow residual. a, Annual log GDP per capita for Mexico (solid line) and Canada (dashed line). $b$, Annual log Solow residual for Mexico and Canada. All values are expressed as deviations from 1981. See the Appendix for data sources and construction of the Solow residual. 
The parameter $\Gamma_{t}$ represents the cumulative product of "growth" shocks. In particular,

$$
\begin{aligned}
& \Gamma_{t}=e^{g} \Gamma_{t-1}=\prod_{s=0}^{t} e^{g_{s}}, \\
& g_{t}=\left(1-\rho_{g}\right) \mu_{g}+\rho_{g} g_{t-1}+\epsilon_{t}^{g},
\end{aligned}
$$

where $\left|\rho_{g}\right|<1$, and $\epsilon_{t}^{g}$ represents independently and identically distributed draws from a normal distribution with zero mean and standard deviation $\sigma_{g}$. The term $\mu_{g}$ represents productivity's long-run mean growth rate. We loosely refer to the realizations of $g$ as the growth shocks since they constitute the stochastic trend of productivity. We use separate notation for shocks to the level of productivity $\left(z_{t}\right)$ and the growth of productivity $\left(g_{t}\right)$ to simplify the exposition and calibration. ${ }^{5}$

Given that a realization of $g$ permanently influences $\Gamma$, output is nonstationary with a stochastic trend. For any variable $x$, we introduce a hat to denote its detrended counterpart:

$$
\hat{x}_{t} \equiv \frac{x_{t}}{\Gamma_{t-1}}
$$

Note that we normalize by trend productivity through period $t-1$. This ensures that if $x_{t}$ is in the agent's information set as of time $t-1$, so is $\hat{x}_{t}$. The solution to the model is invariant to the choice of normalization.

Period utility is Cobb-Douglas,

$$
u_{t}=\frac{\left[C_{t}^{\gamma}\left(1-L_{t}\right)^{1-\gamma}\right]^{1-\sigma}}{1-\sigma},
$$

where $0<\gamma<1$. For well-behaved consumption of the linearized model in the steady state, we require $\beta\left(1+r^{*}\right)=e^{\mu_{g}[1-\gamma(1-\sigma)]} .6$

The equilibrium is characterized by maximizing the present dis-

${ }^{5}$ Of course, given the nature of the production function, we could designate a single productivity shock (equal to the product of $e^{z}$ and $\Gamma^{\alpha}$ ) that would have a corresponding, more complicated dynamic process that would be isomorphic to our approach.

${ }^{6}$ We have also considered quasi-linear preferences ("GHH" preferences introduced by Greenwood, Hercowitz, and Huffman [1988]) that take the form $u_{t}=\left(C_{t}-\right.$ $\left.\tau \Gamma_{t-1} L_{t}^{v}\right)^{1-\sigma} /(1-\sigma)$. These preferences have been used to generate large responses of consumption and labor to productivity shocks. This follows from the high degree of substitutability between leisure and consumption in the utility function, which eliminates the income effect on labor supply. As shown in Aguiar and Gopinath (2005), the main result concerning the relative importance of trend shocks is robust to these alternative preferences. 
counted value of utility subject to the production function (1) and the per period resource constraint:

$$
C_{t}+K_{t+1}=Y_{t}+(1-\delta) K_{t}-\frac{\phi}{2}\left(\frac{K_{t+1}}{K_{t}}-e^{\mu_{g}}\right)^{2} K_{t}-B_{t}+q_{t} B_{t+1} .
$$

Capital depreciates at the rate $\delta$, and changes to the capital stock entail a quadratic adjustment cost

$$
\frac{\phi}{2}\left(\frac{K_{t+1}}{K_{t}}-e^{\mu_{g}}\right)^{2} K_{t}
$$

We assume that international financial transactions are restricted to oneperiod, risk-free bonds. The level of debt due in period $t$ is denoted $B_{t}$, and $q_{t}$ is the time $t$ price of debt due in period $t+1$. The price of debt is sensitive to the level of outstanding debt, taking the form used in Schmitt-Grohe and Uribe (2003): ${ }^{7}$

$$
\frac{1}{q_{t}}=1+r_{t}=1+r^{*}+\psi\left[\exp \left(\frac{B_{t+1}}{\Gamma_{t}}-b\right)-1\right]
$$

where $r^{*}$ is the world interest rate, $b$ represents the steady-state level of normalized debt, and $\psi>0$ governs the elasticity of the interest rate to changes in indebtedness. In choosing the optimal amount of debt, the representative agent does not internalize the fact that she faces an upward-sloping supply of loans.

In normalized form, the representative agent's problem can be stated recursively:

$$
V(\hat{K}, \hat{B}, z, g)=\max _{\left\{\hat{C}, L, \hat{K}^{\prime}, \hat{B}^{\prime}\right\}}\left\{\frac{\left[\hat{C}^{\gamma}(1-L)^{1-\gamma}\right]^{1-\sigma}}{1-\sigma}+\beta e^{g \gamma(1-\sigma)} E V\left(\hat{K}^{\prime}, \hat{B}^{\prime}, z^{\prime}, g^{\prime}\right)\right\}
$$

subject to

$$
\hat{C}+e^{g} \hat{K}^{\prime}=\hat{Y}+(1-\delta) \hat{K}-\frac{\phi}{2}\left(e^{g} \frac{\hat{K}^{\prime}}{\hat{K}}-e^{\mu_{g}}\right)^{2} \hat{K}-\hat{B}+e^{g} q \hat{B}^{\prime} .
$$

${ }^{7}$ This adjustment is typically motivated by the need to make assets in the linearized model stationary. An alternative is to recognize that we are linearly approximating a nonlinear economy for which a stationary distribution exists (e.g., because of borrowing constraints and a world equilibrium interest that is lower than the discount rate, as in Aiyagari [1994]). Quantitatively, since the elasticity of interest rate to changes in indebtedness is set close to zero ( 0.001 to be exact), there is a negligible difference between the two approaches in terms of the Hodrick-Prescott-filtered or first-differenced moments of the model. 
The evolution of the capital stock is given by

$$
e^{g} \hat{K}^{\prime}=(1-\delta) \hat{K}+\hat{X}-\frac{\phi}{2}\left(\frac{\hat{K}^{\prime}}{\hat{K}} e^{g}-e^{\mu_{g}}\right)^{2} \hat{K}
$$

Given an initial capital stock, $\hat{K}_{0}$, and debt level, $\hat{B}_{0}$, the equilibrium of the economy is characterized by the first-order conditions of the problem (6), the technology (1) and budget (7) constraints, and the transversality conditions.

A well-known implication of Cobb-Douglas preferences is the limited response of labor to persistent movements in productivity. The lack of a strong labor response may be less of an issue in emerging markets. Existing data suggest that the correlation of hours with output is much lower in emerging markets (e.g., 0.52 for Argentina and 0.57 for Mexico compared with 0.86 for Canada), suggesting room for a stronger income effect on labor supply over the cycle. However, the income effect implicit in Cobb-Douglas preferences may still be too strong, potentially generating an initial decline in the labor supply in response to a positive shock to trend growth. An alternative approach is to use quasi-linear preferences, as in Greenwood et al. (1988). We have estimated the model using these alternative preferences and obtained similar results in terms of the importance of the stochastic trend (see Aguiar and Gopinath 2005). Moreover, we have also estimated the model with inelastic labor supply, and again, the results concerning the relative volatility of the stochastic trend remain. Given these results and the measurement issues surrounding the data on employment in emerging markets, we do not attempt to match the observed pattern for hours.

We solve the normalized model numerically by log-linearizing the firstorder conditions and resource constraints around the deterministic steady state. Given a solution to the normalized equations, we can recover the path of the nonnormalized equilibrium by multiplying through by $\Gamma_{t-1}$. We also compute the theoretical moments of the model from the coefficients of the linearized solution.

\section{Estimation}

In this section, we estimate the relative importance of trend and transitory shocks to productivity in emerging and developed markets. As a benchmark, we use data from Mexico and Canada to represent the two kinds of markets, respectively.

\section{A. Direct Estimation}

First, we explore direct estimation of the underlying trend process using data on the Solow residual. As is well known, we show that such an 
approach, with the short time series of available data, is inconclusive. We find estimates consistent with the permanent component in Mexico being larger than in Canada. However, the results are sensitive to assumptions about lag length, and the standard errors of the estimates are large. This motivates the methodology we present in the next subsection.

To set notation, recall that the log of the Solow residual in the model is $s r_{t}=z_{t}+\alpha \ln \Gamma_{t}$. We can rewrite $s r_{t}$ as the sum of a random walk component $\tau_{t}$ and a transitory component $s_{t}$. Beveridge and Nelson (1981) show that such a decomposition always exists for an $\mathrm{I}(1)$ process:

$$
s r_{t}=\tau_{t}+s_{t}
$$

where

$$
\tau_{t}=\alpha \mu_{g}+\tau_{t-1}+\left(\frac{\alpha}{1-\rho_{g}}\right) \epsilon_{t}^{g}
$$

is a random walk (with drift) and

$$
s_{t}=z_{t}-\left(\frac{\alpha \rho_{g}}{1-\rho_{g}}\right)\left(g_{t}-\mu_{g}\right)
$$

is a stationary series.

The relative magnitudes of $\sigma_{g}$ and $\sigma_{z}$ (as well as the respective autocorrelations) capture the importance of trend versus transitory shocks. A natural measure of the importance of trend shocks is the variance of $\Delta \tau$ relative to the overall variance of $\Delta s r$ :

$$
\frac{\sigma_{\Delta \tau}^{2}}{\sigma_{\Delta s r}^{2}}=\frac{\alpha^{2} \sigma_{g}^{2}}{\left(1-\rho_{g}\right)^{2} \sigma_{\Delta s r}^{2}} .
$$

This is the conceptual measure advocated in Cochrane (1988). Cochrane shows that

$$
\lim _{K \rightarrow \infty} K^{-1} \operatorname{Var}\left(s r_{t}-s r_{t-K}\right)=\sigma_{\Delta \tau}^{2} .
$$

The relative variance $\sigma_{\Delta \tau}^{2} / \sigma_{\Delta s r}^{2}$ can be approximated empirically by fixing $K$ and calculating the sample variances of $s r_{t}-s r_{t-K}$ and $\Delta s r .{ }^{8}$ The key challenge in practice is that (13) is valid only when $K$ is very large. This is particularly troubling in the present context with only 25 years or so of data for many emerging markets. Choosing a relatively small lag length $K$ will provide a good approximation only if the autocovariances go to zero quickly enough.

This is a well-known empirical issue. The difficulty of detecting a unit

${ }^{8}$ As in Cochrane (1988), we correct the sample variances for small-sample bias by including a degrees of freedom correction $T /(T-K+1)$. 
root in a finite time series, much less accurately measuring its relative contribution to overall variance, is the subject of a large literature (see the discussion in Hamilton [1994, chap. 15]). In particular, $\sigma_{\Delta \tau}^{2} / \sigma_{\Delta s r}^{2}$ represents the normalized spectrum at frequency zero and therefore can be represented by $1+2 \sum_{k=1}^{\infty} \rho\left(\Delta s r_{t}, \Delta s r_{t-j}\right)$, where $\rho(x, y)$ denotes the correlation between $x$ and $y$. Note that all autocorrelations enter equally in the infinite sum. In general, the spectrum at zero cannot be estimated without an infinitely long series. In practice, one can fix a maximum lag length $K$ and assume that the remaining autocorrelations are zero. In assessing the validity of this assumption, simply testing whether the autocorrelations are significantly different from zero is not sufficient. Even if the autocorrelations become individually small after a certain lag length, they may still represent an important component in the infinite sum.

We estimate $\sigma_{\Delta \tau}^{2} / \sigma_{\Delta s r}^{2}$ for various choices of $K$ using annual data on Solow residuals from Mexico and Canada for the period 1981-2002. ${ }^{9}$ The Appendix contains details of how we construct the Solow residuals. The estimates are depicted in figure 2. One indicator of whether truncating $K$ biases our estimates is how sensitive the results are to changes in $K$. As one might expect, given the previous discussion, we find that the results are indeed sensitive to the choice of $K$. For $K=12$ years (or roughly half the sample lengths), we find that the relative variance of the random walk component is 1.72 for Mexico and 0.82 for Canada. These estimates support our premise that the stochastic trend is relatively more important in emerging markets. However, if we shorten $K$ to gain more precision at the cost of increased potential bias, the results are reversed. The relative variance of the random walk component for $K=4$ years is 1.23 for Mexico and 1.70 for Canada. Furthermore, the standard errors are large, and accordingly there is limited power in distinguishing between the random walk components of the two series. ${ }^{10}$ In short, a univariate approach to this issue is bound to be inconclusive.

\section{B. Structural Estimation}

In an environment in which agents have information regarding the persistence of the shock and respond in an optimizing manner, the behavior of macroeconomic aggregates such as consumption, investment, and net exports can be used to unearth the underlying produc-

${ }^{9}$ We have performed the same analysis with $\log$ GDP per capita for each country and obtained similar results.

${ }^{10}$ For $K=12(4)$, the standard errors are $1.50(0.71)$ and $0.62(0.86)$ for Mexico and Canada, respectively. As shown by Cochrane (1988), the asymptotic variance of our measure of $\sigma_{\Delta \tau}^{2}$ is $4 K \sigma_{\Delta \tau}^{4} / 3 T$. The reported standard error is the square root of this quantity divided by the sample counterpart of $\sigma_{\Delta s r}^{2}$ 


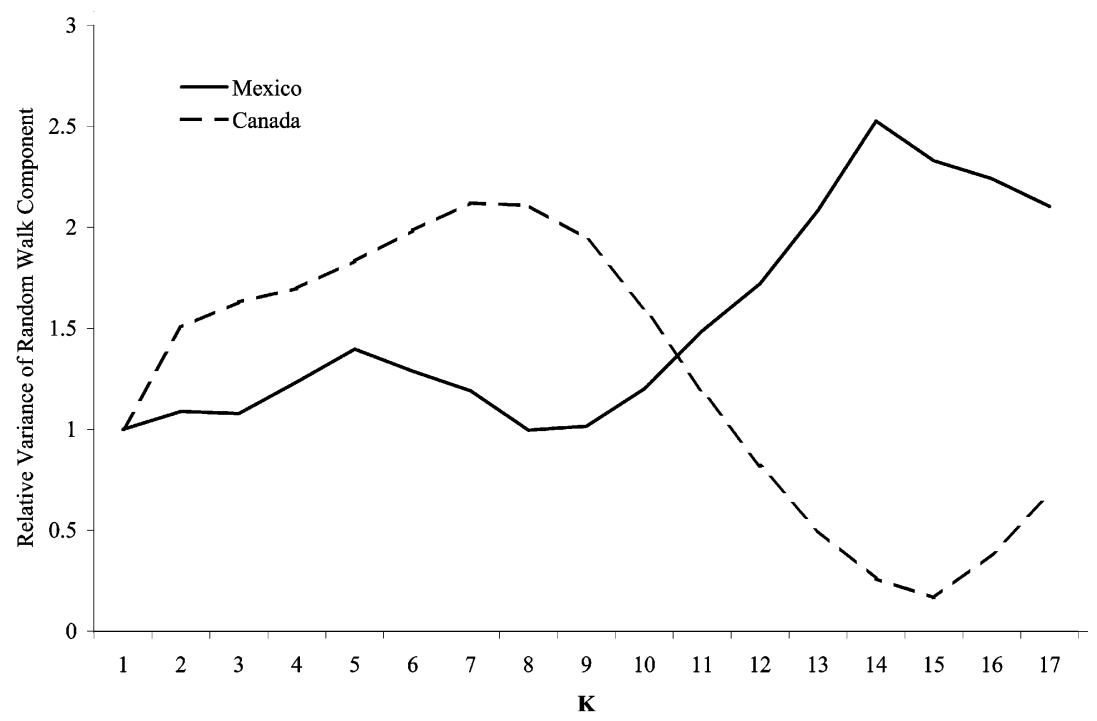

Fig. 2.-Random walk component of the Solow residual. This figure plots $\sigma_{\Delta \tau}^{2} / \sigma_{s s}^{2}$, where $\sigma_{\Delta \tau}^{2}$ is estimated as $T /[K(T-K)(T-K+1)] \sum_{t=K}\left(y_{t}-y_{t-K}-K \mu\right)^{2} ; y_{t}$ is the log Solow residual at time $t$, and $\mu$ is the sample average of the growth rate of the Solow residual. Each point corresponds to the choice of $K$ depicted on the horizontal axis. $\sigma_{s r}^{2}$ is the value of $\sigma_{\Delta \tau}^{2}$ when $K=1$ (i.e., the variance of the first difference of $\log$ Solow residuals). The solid line depicts Mexico and the dashed line depicts Canada.

tivity process. The univariate approach discussed above ignores this information. In particular, given a world interest rate, movements in consumption track movements in permanent income. Our identification strategy exploits this by using the dynamic stochastic equilibrium model to map the actions of optimizing agents into underlying productivity parameters.

Consumption data combined with the permanent income hypothesis have been used successfully by previous authors in related contexts. Two prominent examples include the studies by Cochrane (1994), who uses consumption to identify permanent innovations to GDP in a vector autoregression, and Blundell and Preston (1998), who use the crosssectional dispersion of consumption across households to identify whether income inequality is transitory or permanent in nature. A related point is made by Campbell and Deaton (1989), who note that the permanent income hypothesis implies that if consumption is less volatile than income, then fluctuations in the permanent component of income are a relatively small part of overall income volatility, and vice versa.

Our main focus is to contrast estimates of the importance of trend versus transitory shocks to productivity across emerging and developed economies. Accordingly, we fix all other parameters to be constant across 
TABLE 3

Benchmark Parameter Values

\begin{tabular}{llc}
\hline \hline Time preference rate & $\beta$ & .98 \\
Consumption exponent (utility) & $\gamma$ & .36 \\
Steady-state normalized debt & $b$ & $10 \%$ \\
Coefficient on interest rate & & \\
$\quad$ premium & $\psi$ & .001 \\
Labor exponent (production) & $\alpha$ & .68 \\
Risk aversion & $\sigma$ & 2 \\
Depreciation rate & $\delta$ & .05 \\
Capital adjustment cost & $\phi$ & 4.0 \\
\hline Note.-Benchmark parameters are used in all specifications. The capital adjust- \\
ment cost parameter is set at 4, except for specification 4 of table 4, where it is \\
estimated.
\end{tabular}

emerging and developed market specifications. We calibrate the nonproductivity parameters using standard values from the literature. These are detailed in table 3 . We take a period in the model to represent a quarter. The quarterly discount rate $\beta$ is set to 0.98 , and the risk-free world interest rate is set to satisfy the condition that $\beta\left(1+r^{*}\right)=$ $e^{\mu_{g}[1-\gamma(1-\sigma)]}$. We set $\gamma=0.36$, implying that the steady-state share of time devoted to labor is one-third. The parameter for risk aversion is set at two and the depreciation rate at 0.05 . The coefficient on the interest rate premium term is set at 0.001 , which is the number used in the literature (Schmitt-Grohe and Uribe 2003; Neumeyer and Perri 2005). The steady-state level of debt to GDP is set at 0.1 for both specifications. The results are insensitive to alternate levels of steady-state debt to GDP. The capital adjustment cost parameter $\phi$ is set at four, except for one specification when it is estimated.

\section{Informative Moments}

Before implementing the estimation strategy, we provide some insight into which moments are particularly informative regarding the parameters of the underlying productivity process. For this purpose we contrast the impulse responses following a 1 percent transitory shock (i.e., $\epsilon_{1}^{z}=.01$ ) with the impulse responses to a 1 percent growth shock (i.e., $\left.\epsilon_{1}^{g}=.01\right)$. Figure 3 depicts the response under a "baseline" parameterization that is chosen to anchor the comparative statics within the range of parameters estimated in the next subsection. These parameters are reported in the legend to figure 3.

The ratio of net exports to income has a positive response to a transitory productivity shock (with an autoregressive coefficient of 0.95 ). Given that output remains above trend throughout the transition, a shock to $z$ tends to produce a positive relationship between output and the trade balance. The response of the trade balance to a shock to trend 
growth is markedly different. Following a 1 percent growth shock, the trade balance deficit is 0.5 percent of GDP on impact, and the deficit persists for 14 quarters following the shock.

This difference in the response of net exports arises from the differential response of consumption. As a trend shock implies a greater increase in permanent income, consumption will respond more to such shocks. This can be seen in figure $3 b$. In response to a growth shock, consumption responds more than income given the anticipation of even higher income in the future. The higher future income follows from the fact that the innovation to productivity is not expected to die out and capital adjusts gradually. Further, in this parameterization, growth is positively autocorrelated. On the other hand, the transitory shock induces saving in anticipation of lower income in the future as productivity mean-reverts. This results in a decline in the consumption to income ratio on impact. The initial response of investment (as a fraction of income) is slightly larger for a growth shock. Moreover, the response of investment to a trend shock is naturally more persistent.

The sharp difference in the impulse responses of consumption, investment, and net exports to a trend and transitory shock highlights why data on these variables can help us infer the underlying productivity process. In theory, there are potentially a large number of moments that one can match to estimate the underlying parameters. The impulse responses suggest that a small subset of these moments, namely the volatility of consumption and the comovement of net exports with GDP, are particularly informative.

To provide further guidance about which moments are informative, in figure 4 we plot theoretical moments of the model for various values of the ratio $\sigma_{g} / \sigma_{z}$, holding all other parameters fixed at their baseline values. We anchor $\sigma_{z}$ at 0.5 percent and vary $\sigma_{g}$, keeping in mind that it is the ratio $\sigma_{g} / \sigma_{z}$ that determines the relative variances and covariances in the linearized model.

Figure $4 a$ plots the standard deviation of filtered consumption, investment, and net exports as ratios of the standard deviation of filtered income. As we increase the relative variance of the trend shocks, we see that consumption, investment, and net exports all increase their volatility relative to income. In percentage terms, the increase is largest for net exports and consumption.

In figure $4 b$, we plot the correlations of filtered consumption, investment, and net exports with filtered income. We also plot the autocorrelation of filtered income and the autocorrelation of the growth of (unfiltered) income. The moment most sensitive to the relative magnitude of $\sigma_{g}$ is the correlation of net exports with income. This ranges from 0.7 when there are only transitory shocks to -0.6 when trend shocks are five times as volatile as transitory shocks. 

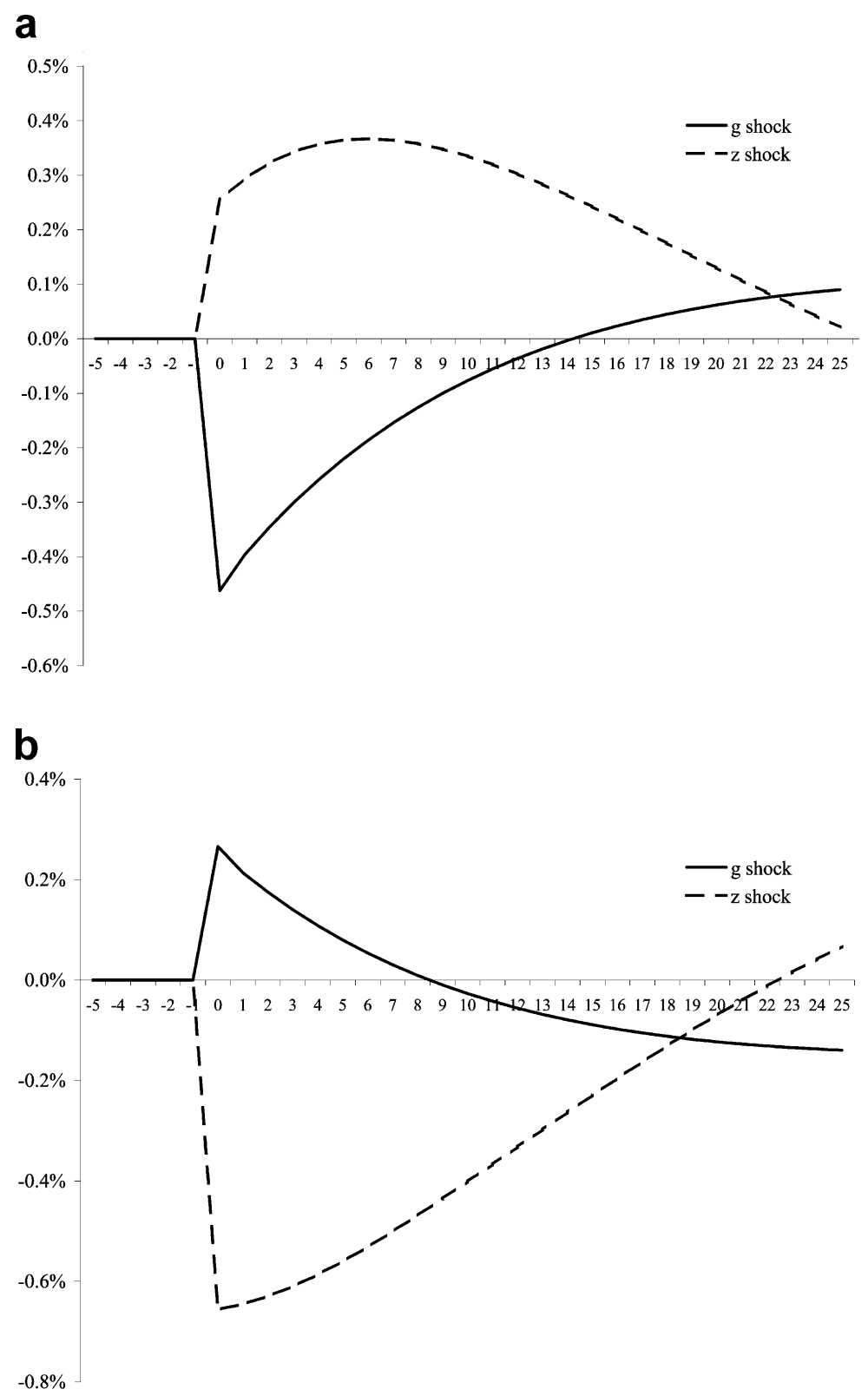

FIG. 3.-Impulse responses. $a$, Ratio of net exports to GDP. $b$, Ratio of consumption to GDP. $c$, Ratio of investment to GDP. Impulse response of net exports, consumption, and investment relative to income in response to a 1 percent shock to $\epsilon^{g}$ ( $g$ shock, solid line) and a 1 percent shock to $\epsilon^{z}$ ( $z$ shock, dashed line). The values plotted are deviations from the steady state. The parameters $\rho_{g}$ and $\rho_{z}$ are set to 0.01 and 0.95 , respectively. All other parameters are as reported in table 3. 


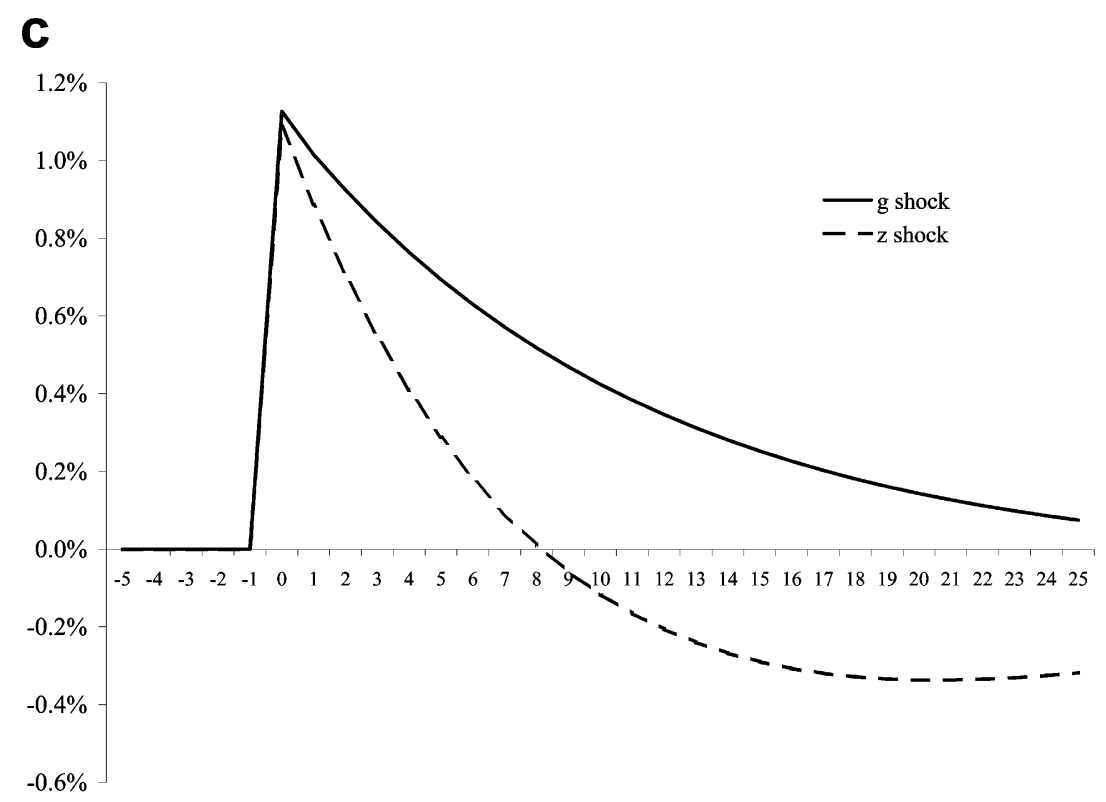

FIG. 3.-(Continued)

It is important to note that the autocorrelation of filtered income does not appear to be sensitive to variation in $\sigma_{g} / \sigma_{z}$, ranging from 0.75 to 0.78 . This is consistent with the data for emerging and developed markets. When we compare the autocorrelation parameter of filtered output across emerging and developed markets, there is very little difference in this persistence parameter (see table 1). Note as well that the correlation of consumption with income is not strongly related to $\sigma_{g} / \sigma_{z^{*}}$. While trend shocks generate a large response of consumption to a movement in income, this does not necessarily translate into a higher correlation at business cycle frequencies. The fact that trend shocks are autocorrelated and generate a prolonged period of investment implies that the initial response of income may be smaller than its long-run response. This effect lowers the high-frequency correlation of income and consumption.

The results in figure 4 confirm the intuition from the impulse response functions that the variances of consumption and net exports, as well as the correlation of net exports to income, are particularly informative regarding the importance of trend shocks to productivity. On the other hand, the autocorrelation of output and the correlation of consumption and investment with output do not appear to be as informative. 


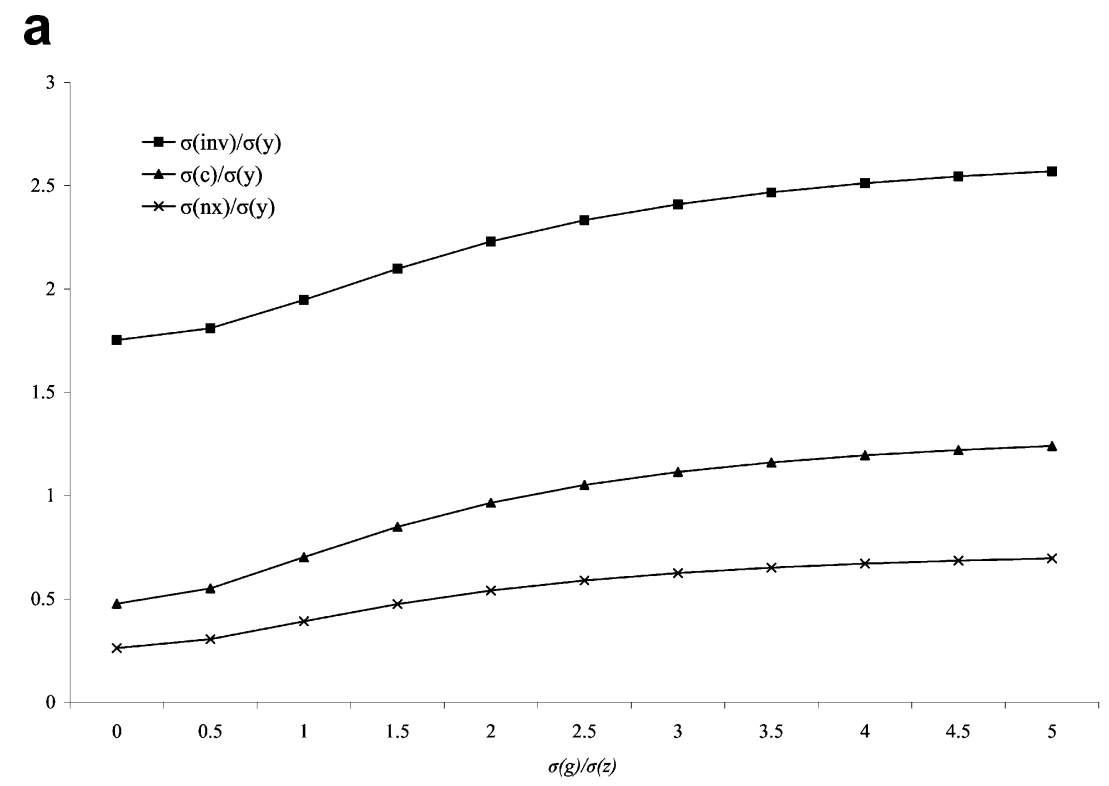

b

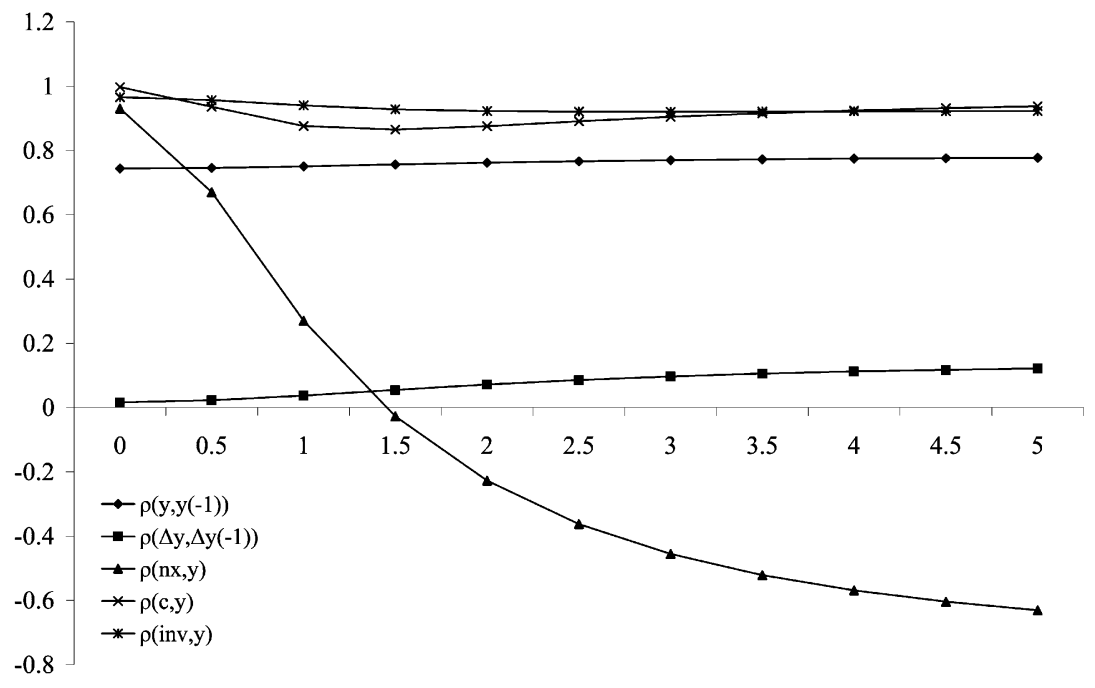

$\sigma(g) / \sigma(z)$

FIG. 4.-Sensitivity of moments to the relative volatility of trend shocks. $a$, The standard deviation of filtered investment, consumption, and net exports relative to the standard deviation of filtered income as a function of alternative $\sigma_{g} / \sigma_{z} . b$, The autocorrelation of filtered income, the autocorrelation of unfiltered income growth, and the contemporaneous correlations of filtered net exports, consumption, and investment with filtered income as functions of alternative $\sigma_{g} / \sigma_{z}$. 
TABLE 4

Estimated Parameters

\begin{tabular}{|c|c|c|c|c|c|c|c|c|}
\hline \multirow[b]{2}{*}{ PARAMETER } & \multicolumn{4}{|c|}{ Mexico } & \multicolumn{4}{|c|}{ CANADA } \\
\hline & 1 & 2 & 3 & 4 & 1 & 2 & 3 & 4 \\
\hline$\sigma_{g}$ & $\begin{array}{l}2.81 \\
(.37)\end{array}$ & $\begin{array}{l}3.06 \\
(.56)\end{array}$ & $\begin{array}{l}2.55 \\
(.52)\end{array}$ & $\begin{array}{l}2.13 \\
(.29)\end{array}$ & $\begin{array}{l}.88 \\
(.18)\end{array}$ & $\begin{array}{l}1.20 \\
(.32)\end{array}$ & $\begin{array}{l}.87 \\
(.61)\end{array}$ & $\begin{array}{c}.47 \\
(.37)\end{array}$ \\
\hline$\sigma_{z}$ & $\begin{array}{l}.48 \\
(.27)\end{array}$ & $\begin{array}{l}.17 \\
(.65)\end{array}$ & $\begin{array}{l}.54 \\
(.22)\end{array}$ & $\begin{array}{l}.53 \\
(.34)\end{array}$ & $\begin{array}{l}.78 \\
(.09)\end{array}$ & $\begin{array}{l}.69 \\
(.06)\end{array}$ & $\begin{array}{l}.78 \\
(.08)\end{array}$ & $\begin{array}{c}.63 \\
(.14)\end{array}$ \\
\hline$\rho_{g}$ & & & $\begin{array}{l}.11 \\
(.10)\end{array}$ & $\begin{array}{l}.00 \\
(.05)\end{array}$ & & & $\begin{array}{l}.03 \\
(.54)\end{array}$ & $\begin{array}{l}.29 \\
(.36)\end{array}$ \\
\hline$\rho_{z}$ & & & & $\begin{array}{l}.95 \\
(.09)\end{array}$ & & & & $\begin{array}{c}.97 \\
(.02)\end{array}$ \\
\hline$\mu_{g}$ & & & & $\begin{array}{l}.66 \\
(.15)\end{array}$ & & & & $\begin{array}{l}.73 \\
(.13)\end{array}$ \\
\hline$\varphi$ & & & & $\begin{array}{l}1.37 \\
(.39)\end{array}$ & & & & $\begin{array}{l}1.78 \\
(.45)\end{array}$ \\
\hline $\begin{array}{l}\text { Random walk } \\
\text { component }\end{array}$ & $\begin{array}{l}.96 \\
(.07)\end{array}$ & $\begin{array}{l}1.01 \\
(.06)\end{array}$ & $\begin{array}{l}1.13 \\
(.05)\end{array}$ & $\begin{array}{l}.88 \\
(.11)\end{array}$ & $\begin{array}{l}.37 \\
(.07)\end{array}$ & $\begin{array}{l}.59 \\
(.13)\end{array}$ & $\begin{array}{l}.38 \\
(.29)\end{array}$ & $\begin{array}{c}.40 \\
(.24)\end{array}$ \\
\hline $\begin{array}{l}\text { Moments } \\
\text { used }\end{array}$ & $\sigma_{y}, \sigma_{c}$ & $\begin{array}{c}\sigma_{y}, \\
\operatorname{Cov}(\mathrm{NX}, y)\end{array}$ & $\begin{array}{c}\sigma_{y}, \sigma_{c} \\
\operatorname{Cov}(c, y)\end{array}$ & All & $\sigma_{y}, \sigma_{c}$ & $\begin{array}{c}\sigma_{y}, \\
\operatorname{Cov}(\mathrm{NX}, y)\end{array}$ & $\begin{array}{c}\sigma_{y}, \sigma_{c} \\
\operatorname{Cov}(c, y)\end{array}$ & All \\
\hline
\end{tabular}

NoTE. -GMM estimates with standard errors in parentheses. Moments used refers to which empirical moments were matched during estimation. "All" refers to the following 11 moments: the standard deviations of income, consumption, investment, net exports, and first-differenced (unfiltered) income; the covariances of income with lagged income, consumption, investment, and net exports; the autocovariance of first-differenced (unfiltered) income; and the mean of first-differenced (unfiltered) income. The random walk component is calculated as in eq (14). Standard devians of first-differ, are reported in percentage terms. All parameters not estimated in each specification were fixed at the benchmark
values reported in table 3 . When not estimated, we set $\rho_{g}=0.01$ and $\rho_{z}=0.95$.

\section{Results}

\section{A. Parameter Estimates}

In this subsection, we estimate the parameters of the model by matching the relatively informative moments discussed in the previous section. Specifically, the theoretical moments of the model are functions of the underlying parameters. We estimate the parameters using GMM by minimizing the squared difference between the model and empirical moments. When the number of moments exceeds the number of parameters, we use the optimal weighting matrix as described by Hansen (1982). We begin by estimating the two variance parameters, $\sigma_{g}$ and $\sigma_{z}$, and then estimate the full set of productivity parameters.

Figure 4 and the intuition of the permanent income hypothesis suggest that the relative variance of consumption is particularly informative regarding the importance of trend shocks. Column 1 of table 4 reports the estimates of $\sigma_{g}$ and $\sigma_{z}$ obtained by matching the empirical standard deviations of filtered income and consumption. With two parameters and two moments, we match the two empirical moments exactly. For Mexico, we estimate $\sigma_{g}=2.81$ and $\sigma_{z}=0.48$. For Canada, our estimates 
are 0.88 and 0.78 , respectively. The random walk component of the Solow residual from equation (12) can be expressed as

$$
\frac{\sigma_{\Delta \tau}^{2}}{\sigma_{\Delta s r}^{2}}=\frac{\alpha^{2} \sigma_{g}^{2} /\left(1-\rho_{g}\right)^{2}}{\left[2 /\left(1+\rho_{z}\right)\right] \sigma_{z}^{2}+\left[\alpha^{2} \sigma_{g}^{2} /\left(1-\rho_{g}^{2}\right)\right]} .
$$

Our estimates imply that this ratio is 0.96 for Mexico and 0.37 for Canada. We can reject that these ratios are the same at all standard levels of statistical significance.

The previous section also highlighted the cyclicality of net exports as an informative moment. Column 2 reestimates $\sigma_{g}$ and $\sigma_{z}$ by matching the variance of income and the covariance of net exports with income. The estimates are similar. In particular, the relative importance of the random walk component is 1.01 for Mexico and 0.59 for Canada ( $p$-value of the difference $<0.01)$.

The importance of the random walk component does not depend only on $\sigma_{g}$ and $\sigma_{z}$. From (12), the variance of the random walk component is $\alpha^{2} \sigma_{g}^{2} /\left(1-\rho_{g}\right)^{2}$ and therefore is sensitive to our choice of $\rho_{g}$. An increase in either $\sigma_{g}$ or $\rho_{g}$ raises the variance of the random walk component. However, a shock to productivity today has a larger impact on future productivity realizations the larger $\rho_{g}$ is. This lowers the contemporaneous correlation of consumption with current income. For example, when the parameters of column 1 for Mexico are used, the correlation of consumption and income is 0.94 . When all other parameters are held constant, with $\rho_{g}$ changed from 0.01 to 0.25 , the correlation decreases to 0.86 . Recall that the correlation of consumption with income was not responsive to $\sigma_{g} / \sigma_{z}$. Therefore, this correlation helps identify whether the random walk component is driven by $\sigma_{g}$ or $\rho_{g}$.

In column 3 we report estimates of the vector of parameters $\left(\sigma_{g}, \sigma_{z}\right.$, $\left.\rho_{g}\right)$. We do so by matching the variances of output and consumption as well as the covariance of consumption with output. For both Mexico and Canada, the estimates of $\sigma_{g}$ and $\sigma_{z}$ in column 3 are similar to those in column 1. The respective estimates of $\rho_{g}$ are 0.11 and 0.03 . The precision of the estimate of $\rho_{g}$ for Canada is lower since trend shocks are relatively unimportant. The relative variance of the random walk component is 1.13 for Mexico and 0.37 for Canada ( $p$-value of the difference $=0.02$ ).

Finally, in column 4 we estimate the full set of productivity parameters as well as the capital adjustment cost parameter $\phi$. To estimate these parameters, we match the 10 moments reported in table 2 plus the average growth rate of unfiltered income. The estimates are consistent with previous estimates.

It is important to note that the measure of the random walk component for each country is largely invariant across the particular spec- 
ification used or when we move from estimating only $\sigma_{z}$ and $\sigma_{g}$ to estimating a larger set of productivity parameters (cols. 1-4). The random walk component for Mexico ranges between 0.88 and 1.13, whereas for Canada it ranges between 0.37 and 0.59 . This reflects the fact that the key information regarding the importance of permanent shocks is captured in consumption and net exports.

\section{B. Business Cycle Moments}

In this subsection, we compute a broad set of theoretical moments using the parameters estimated above. Given the respective productivity parameters, we show that a standard equilibrium model matches the key business cycle features of both emerging and developed economies.

In table 5, we report the theoretical moments, using the estimates of columns 1, 2, and 4 of table 3, and compare them with the data. Note that in specifications 1 and 2, we use only two moments and vary two parameters across Mexico and Canada. Nevertheless, the model does well in matching the overall pattern of business cycles in both economies. When we estimate the full set of productivity parameters using all moments, the implied theoretical moments reported in column 4 are not very different from the estimated moments in specifications 1 and 2. In specification 3, the number of moments exceeds the number of parameters. This allows us to test the overidentifying restrictions of the model. The $J$-test proposed by Hansen (1982) cannot reject the model for either Mexico or Canada (the respective $p$-values are 0.28 and 0.32 ).

The data in table 2 indicate that the volatility of consumption relative to income is much higher in emerging markets. The empirical ratio $\sigma(c) / \sigma(y)$ is 1.26 and 0.74 in Mexico and Canada, respectively. This pattern is generated by the model. Of course, specification 1 matches this moment by design. However, in specification 2, where estimation did not include the variance of consumption, the predicted ratio is 1.33 and 0.91 , respectively. When we match all moments (specification 3), the implied ratios are 1.10 and 0.76 for Mexico and Canada, respectively. The model therefore predicts that consumption volatility should exceed income volatility in emerging markets. Such "excess" volatility is perfectly consistent with optimizing consumers, given the nature of the underlying income process.

In regard to net exports, the emerging market parameterization yields a strongly negative correlation with income. The correlations between net exports and income in specifications 1 and 3 are -0.66 and -0.50 , compared to the observed correlation of -0.75 . The developed parameterization predicts either a mildly procyclical or a mildly countercyclical trade balance. The mild countercyclicality is consistent with the data for Canada. 
TABLE 5

Moments

\begin{tabular}{|c|c|c|c|c|}
\hline & \multirow[b]{2}{*}{ DATA } & \multicolumn{3}{|c|}{ SPECIFICATION } \\
\hline & & 1 & 2 & 3 \\
\hline & \multicolumn{4}{|c|}{ A. Emerging Market: Mexico } \\
\hline$\sigma(y)$ & $\begin{array}{l}2.40 \\
(.35)\end{array}$ & $\begin{array}{l}2.40 \\
(.35)\end{array}$ & $\begin{array}{l}2.46 \\
(.31)\end{array}$ & $\begin{array}{l}2.13 \\
(.27)\end{array}$ \\
\hline$\sigma(\Delta y)$ & $\begin{array}{l}1.52 \\
(.25)\end{array}$ & $\begin{array}{l}1.73 \\
(.26)\end{array}$ & $\begin{array}{l}1.77 \\
(.22)\end{array}$ & $\begin{array}{l}1.42 \\
(.17)\end{array}$ \\
\hline$\sigma(c) / \sigma(y)$ & $\begin{array}{l}1.26 \\
(.08)\end{array}$ & $\begin{array}{l}1.26 \\
(.08)\end{array}$ & $\begin{array}{l}1.33 \\
(.03)\end{array}$ & $\begin{array}{l}1.10 \\
(.05)\end{array}$ \\
\hline$\sigma(I) / \sigma(y)$ & $\begin{array}{l}4.15 \\
(.29)\end{array}$ & $\begin{array}{l}2.60 \\
(.10)\end{array}$ & $\begin{array}{l}2.69 \\
(.04)\end{array}$ & $\begin{array}{l}3.83 \\
(.33)\end{array}$ \\
\hline$\sigma(\mathrm{NX}) / \sigma(y)$ & $\begin{array}{c}.90 \\
(.09)\end{array}$ & $\begin{array}{l}.71 \\
(.04)\end{array}$ & $\begin{array}{c}.75 \\
(.02)\end{array}$ & $\begin{array}{c}.95 \\
(.10)\end{array}$ \\
\hline$\rho(y)$ & $\begin{array}{c}.83 \\
(.07)\end{array}$ & $\begin{array}{l}.78 \\
(.01)\end{array}$ & $\begin{array}{l}.78 \\
(.002)\end{array}$ & $\begin{array}{l}.82 \\
(.02)\end{array}$ \\
\hline$\rho(\Delta y)$ & $\begin{array}{c}.27 \\
(.09)\end{array}$ & $\begin{array}{l}.13 \\
(.02)\end{array}$ & $\begin{array}{l}.14 \\
(.01)\end{array}$ & $\begin{array}{l}.18 \\
(.08)\end{array}$ \\
\hline$\rho(y, \mathrm{NX})$ & $\begin{array}{c}-.75 \\
(.08)\end{array}$ & $\begin{array}{c}-.66 \\
(.10)\end{array}$ & $\begin{array}{c}-.75 \\
(.04)\end{array}$ & $\begin{array}{r}-.50 \\
(.06)\end{array}$ \\
\hline$\rho(y, c)$ & $\begin{array}{c}.92 \\
(.02)\end{array}$ & $\begin{array}{c}.94 \\
(.02)\end{array}$ & $\begin{array}{c}.97 \\
(.01)\end{array}$ & $\begin{array}{l}.91 \\
(.03)\end{array}$ \\
\hline \multirow[t]{2}{*}{$\rho(y, I)$} & $\begin{array}{c}.91 \\
(.03) \\
\end{array}$ & $\begin{array}{c}.92 \\
(.003) \\
\end{array}$ & $\begin{array}{c}.93 \\
(.002) \\
\end{array}$ & $\begin{array}{r}.80 \\
(.03) \\
\end{array}$ \\
\hline & \multicolumn{4}{|c|}{ B. Developed Market: Canada } \\
\hline$\sigma(y)$ & $\begin{array}{l}1.55 \\
(.20)\end{array}$ & $\begin{array}{l}1.55 \\
(.20)\end{array}$ & $\begin{array}{l}1.55 \\
(.20)\end{array}$ & $\begin{array}{l}1.24 \\
(.11)\end{array}$ \\
\hline$\sigma(\Delta y)$ & $\begin{array}{c}.80 \\
(.09)\end{array}$ & $\begin{array}{l}1.14 \\
(.14)\end{array}$ & $\begin{array}{l}1.14 \\
(.15)\end{array}$ & $\begin{array}{c}.82 \\
(.09)\end{array}$ \\
\hline$\sigma(c) / \sigma(y)$ & $\begin{array}{c}.74 \\
(.05)\end{array}$ & $\begin{array}{l}.74 \\
(.05)\end{array}$ & $\begin{array}{c}.91 \\
(.05)\end{array}$ & $\begin{array}{l}.76 \\
(.07)\end{array}$ \\
\hline$\sigma(I) / \sigma(y)$ & $\begin{array}{l}2.67 \\
(.25)\end{array}$ & $\begin{array}{l}1.99 \\
(.05)\end{array}$ & $\begin{array}{l}2.16 \\
(.05)\end{array}$ & $\begin{array}{c}3.14 \\
(.23)\end{array}$ \\
\hline$\sigma(\mathrm{NX}) / \sigma(y)$ & $\begin{array}{c}.57 \\
(.09)\end{array}$ & $\begin{array}{l}.41 \\
(.03)\end{array}$ & $\begin{array}{c}.51 \\
(.03)\end{array}$ & $\begin{array}{l}.65 \\
(.11)\end{array}$ \\
\hline$\rho(y)$ & $\begin{array}{c}.93 \\
(.04)\end{array}$ & $\begin{array}{l}.75 \\
(.002)\end{array}$ & $\begin{array}{l}.76 \\
(.002)\end{array}$ & $\begin{array}{c}.81 \\
(.01)\end{array}$ \\
\hline$\rho(\Delta y)$ & $\begin{array}{c}.55 \\
(.10)\end{array}$ & $\begin{array}{l}.04 \\
(.01)\end{array}$ & $\begin{array}{c}.06 \\
(.01)\end{array}$ & $\begin{array}{c}.17 \\
(.04)\end{array}$ \\
\hline$\rho(y, \mathrm{NX})$ & $\begin{array}{c}-.12 \\
(.18)\end{array}$ & $\begin{array}{l}.18 \\
(.11)\end{array}$ & $\begin{array}{c}-.13 \\
(.08)\end{array}$ & $\begin{array}{r}-.15 \\
(.19)\end{array}$ \\
\hline$\rho(y, c)$ & $\begin{array}{c}.87 \\
(.05)\end{array}$ & $\begin{array}{l}.87 \\
(.01)\end{array}$ & $\begin{array}{l}.87 \\
(.004)\end{array}$ & $\begin{array}{c}.87 \\
(.07)\end{array}$ \\
\hline$\rho(y, I)$ & $\begin{array}{c}.74 \\
(.09)\end{array}$ & $\begin{array}{l}.94 \\
(.004)\end{array}$ & $\begin{array}{l}.93 \\
(.002)\end{array}$ & $\begin{array}{c}.82 \\
(.06)\end{array}$ \\
\hline
\end{tabular}




\section{Solow Residuals}

We have adopted a method of structurally estimating the underlying process of the Solow residual using the information implicit in the decisions made by agents. In this subsection, we compare the implied autocovariances of our estimated Solow residual process to that observed in the data. We have constructed a Solow residual series using the available data on hours, employment, and capital stock for Mexico and Canada. The Appendix contains the details of our calculations. For Mexico, we construct a quarterly series for the Solow residual starting in 1987, and for Canada we calculate the series starting in $1981 .{ }^{11}$

Figure 5 plots the variance and the first eight autocovariances of the Hodrick-Prescott-filtered Solow residual from the data and the model. The model parameters are those of column 3 of table 4 . Figure $5 a$ refers to Mexico and $5 b$ to Canada. We also include \pm 1.5 standard error bands around the empirical estimates. For both countries, the theoretical autocovariances track their empirical counterparts well. All theoretical moments lie within the standard error bands of the empirical moments.

Recall that these parameters were identified using the structural model and observed macroeconomic aggregates and were not estimated using direct measures of the Solow residual. Nevertheless, the estimated model does quite well in matching the autocovariance function of the empirical Solow residuals. Similar patterns emerge using the model estimates from the other columns of table 4 (not depicted). In short, the behavior of consumption and net exports over the business cycle implies productivity parameters that are borne out in the data.

\section{Sudden Stops}

A major challenge to models of emerging markets is explaining the large current-account reversals observed in the data, the so-called sudden stops. The sudden-stop phenomenon has been described in detail in Calvo and Reinhart (2000), Arellano and Mendoza (2002), and Gopinath (2004), among others. It is specifically associated with an abrupt and large reversal in net capital inflows and the current account. An example of the sudden-stop phenomenon is the Mexican Tequila crisis, when there was a 9.6-percentage-point reversal in the ratio of the trade balance to GDP, from a deficit of 3.8 percent to a surplus of 5.7 percent, between the third quarter of 1994 and the second quarter of 1995. Over

\footnotetext{
${ }^{11}$ Our empirical series on Solow residuals is unavoidably noisy because of the limited availability of data for capacity utilization, materials used, a reliable measure of hours worked, etc. In the presence of terms-of-trade shocks and noncompetitive pricing, measuring Solow residuals is even more of a challenge. Nevertheless, we feel that it is a useful consistency check to compare the available Solow residual series to that of a model.
} 


\section{a}

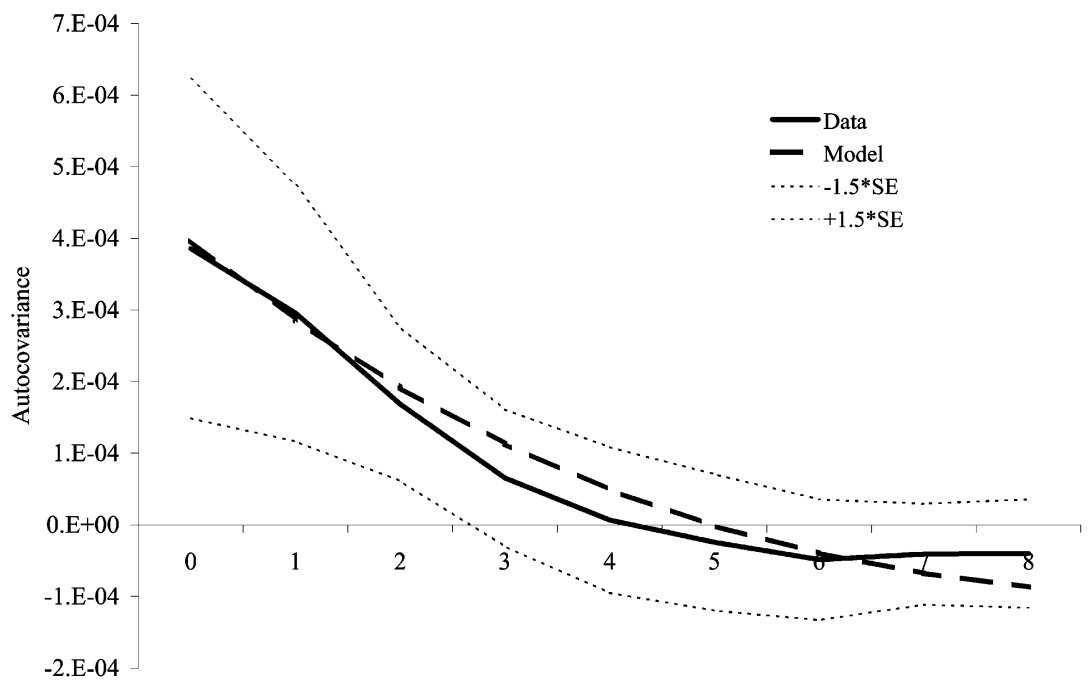

Lag

b

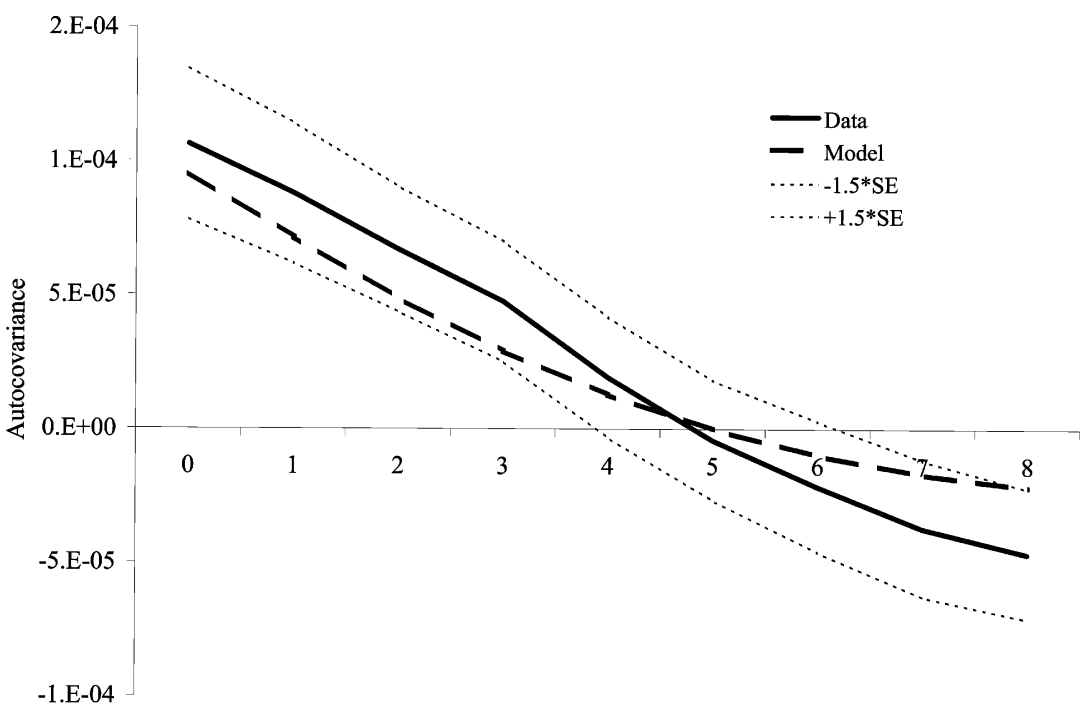

Lag

Fig. 5.-Autocovariance function of the Solow residual: data and model. This figure plots the autocovariance function of filtered $\log$ Solow residuals from the data (solid line) and the model (dashed line) for $(a)$ Mexico and $(b)$ Canada. The model is generated from parameters reported in col. 4 of table 4 . The dashed lines represent 1.5 standard error bounds. 


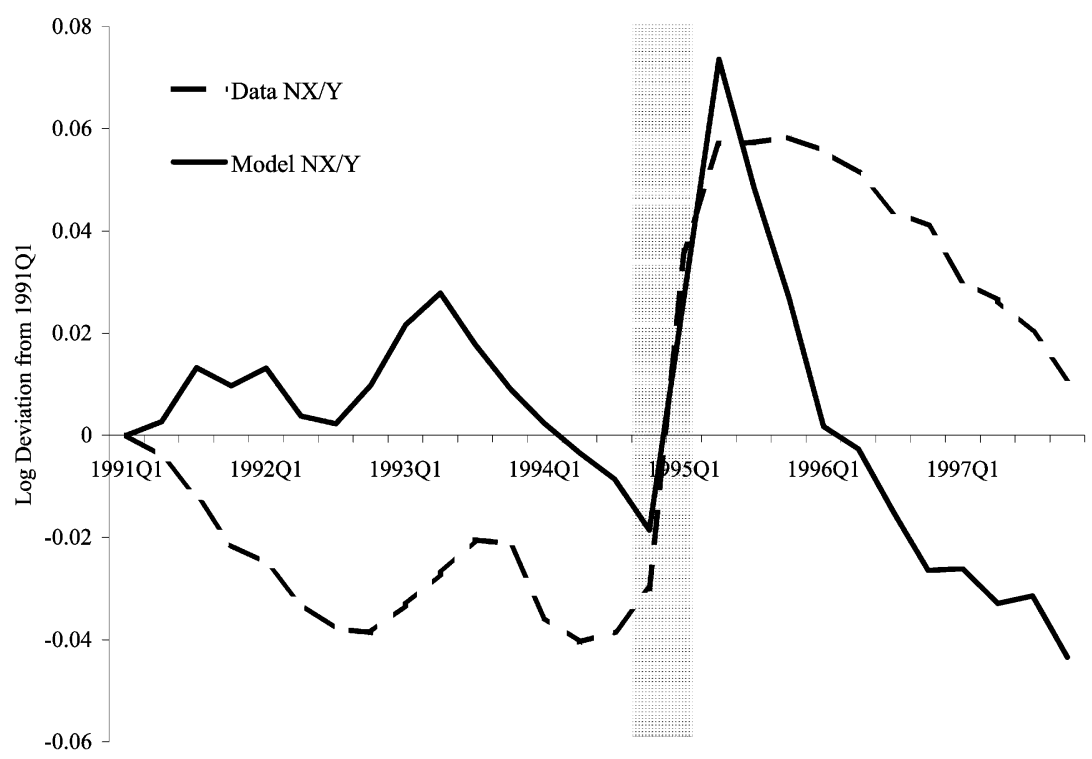

Fig. 6.-Sudden stop-Mexican Tequila crisis (1994-95). The dashed line represents the empirical ratio of net exports to GDP in Mexico. The solid line represents the ratio predicted by the model using the observed Solow residuals and the parameters reported in col. 4 of table 4. Both series are log deviations from 1991Q1.

the same period, output, consumption, and investment all fell dramatically.

We can explore how well our model does in replicating such phenomena by asking whether the observed process for Solow residuals generates a sudden stop when fed into the model. To do this, we first use the Kalman filter and the estimated parameters (specification 4 from table 4) to decompose the Solow residuals calculated using Mexican data into permanent $(g)$ and transitory $(z)$ processes. ${ }^{12}$ We then feed these shocks through our model and calculate the predicted path of net exports for the period surrounding the 1994-95 Tequila crisis in Mexico. We plot the predicted and actual path of net exports as a percentage of GDP in figure 6 , where we have normalized both series to zero for the first quarter of 1991. As the plot indicates, the model generates a clear sudden stop during the Tequila crisis of late 1994. The model predicts a reversal of 8.2 percentage points between the third quarter of 1994 and the second quarter of 1995, similar to the 9.6percentage-point reversal observed in the data. Similarly, and also con-

${ }^{12}$ Specifically, we calculate $E\left\{g_{t} \mid s r_{1}, \ldots, s r_{T}, \theta\right\}$ and $E\left\{z_{t} \mid s r_{1}, \ldots, s r_{T}, \theta\right\}$ for each $t$. The term $s r$ denotes the observed Solow residuals, and $\theta=\left\{\sigma_{z}, \rho_{z}, \sigma_{g}, \rho_{g}, \mu_{g}\right\}$. Note that we use the entire path of Solow residuals for each point in time (the Kalman filter with "smoothing"). 
sistent with the data, the model predicts large contractions in output, consumption, and investment during the crisis (not depicted). The model's prediction of a sudden stop in 1994 stems from the fact that much of the observed drop in the Solow residual can be attributed to a shock to trend. One should keep in mind that this attribution is a product of both the observed path of Solow residuals and the parameters used in constructing the Kalman filter.

\section{Discussion and Conclusion}

In this paper we document several business cycle characteristics that distinguish emerging markets from developed small open economies. We demonstrate that a standard business cycle model can be used to estimate the predominance of shocks to trend growth relative to transitory shocks. The evidence indicates that economic activity observed at business cycle frequencies in emerging markets is driven by shocks to a stochastic trend. Conversely, developed economies have relatively stable trends.

The empirical argument was made using data from Mexico and Canada as representatives of their two respective classes of economies. We have performed the core analysis using data from other small open economies. We find that our respective benchmark economies are indeed representative of emerging and developed economies. Specifically, the relative importance of the random walk component is larger for emerging markets than it is for developed economies. The average random walk component is 0.84 for emerging markets and 0.61 for developed countries.

One striking feature of emerging-market economies is the volatility of interest rates, a feature omitted from the analysis. The role of intertemporal substitution is stressed by Calvo (1986) in explaining consumption booms following noncredible inflation stabilizations. A recent paper by Neumeyer and Perri (2005) addresses business cycles in emerging markets by emphasizing exogenous movements in interest rates and preferences. In our benchmark estimation, movements in consumption are driven by income shocks, with the interest rate remaining essentially fixed given the small value of $\psi$. This raises the concern that we have forced the income process in our benchmark model to explain consumption or investment fluctuations that in reality were due to movements in the interest rate. To address this concern, we have extended the model to incorporate a stochastic interest rate process in addition to the productivity process. The augmented model produces estimates of the income process that are in line with the benchmark model. That is, it is not the case that our permanent shocks were simply proxies for omitted interest rate movements. Aguiar and Gopinath (2005) contains 
the details and results of this analysis. Moreover, in Aguiar and Gopinath (2006), we show that trend shocks play an important role in quantitatively matching the frequency of default in emerging markets.

Our analysis highlights a key difference in the stochastic process for Solow residuals in emerging and developed economies. Given a process for the residuals, a standard equilibrium model matches the business cycle facts well. However, this does not imply that frictions are unimportant. More likely, the properties of the Solow residual are a manifestation of deeper frictions. Our analysis suggests that models with market imperfections that endogenously generate volatile and persistent shocks to total factor productivity may be an important avenue for future research. Conversely, we show that conditional on frictions that manifest as a persistent Solow residual, we do not require additional wedges that distort the response of investment, consumption, and net exports to explain the key features of emerging market business cycles.

Appendix

\section{Data}

\section{A. Business Cycle Data}

The data sources and sample lengths are listed in table A1. The data come from three sources: the Organization for Economic Cooperation and Development (OECD), the Institute for Fiscal Studies (IFS), and Neumeyer and Perri (2005). The original sources of the Neumeyer and Perri (NP) data are reported in the note to table A1. We tested each series for a seasonal component and removed any significant seasonality using the U.S. Census Bureau's X-12 ARIMA seasonal adjustment program. Consumption is "household consumption" and excludes government consumption. When household consumption is unavailable, we use "private consumption," which combines consumption of households and nonprofit institutions. Investment is gross fixed capital formation. Net exports is constructed as the difference between exports and imports. The IFS series are deflated using the GDP deflator. The OECD series are reported by OECD in base year (Korea, Mexico, Slovak Republic, Turkey, Austria, Belgium, Denmark, Finland, Spain, and Switzerland) or chained (Australia, Canada, Netherlands, New Zealand, and Norway) constant prices using the relevant deflator. All data series are available from the authors' Web sites.

\section{B. Construction of Solow Residuals}

Solow residuals are defined as $s r_{t} \equiv \ln \left(Y_{t}\right)-\alpha \ln \left(L_{t}\right)-(1-\alpha) \ln \left(K_{t}\right)$, where $Y$ denotes real GDP, $L$ is a measure of labor inputs, and $K$ is a measure of capital. For both Mexico and Canada, we use $\alpha=0.68$.

We measure $L$ in two ways for each country, using either total employment or total hours. For Canada, employment is the Canadian civilian employment series. To calculate total hours, we use hours per worker in manufacturing as a proxy for average hours per worker and scale the employment series accordingly. For Mexico, the employment series is calculated as $(1-$ unemployment 
TABLE A1

Data Sources

\begin{tabular}{|c|c|c|}
\hline & Quarters & Source \\
\hline \multicolumn{3}{|l|}{ Emerging markets: } \\
\hline Argentina & 1993Q1-2002Q4 & IFS \\
\hline Brazil & 1991Q1-2002Q1 & NP \\
\hline Ecuador & 1991Q1-2002Q2 & IFS \\
\hline Israel & 1980Q1-2003Q1 & IFS \\
\hline Korea & 1979 $44-2003 \widetilde{Q} 2$ & OECD \\
\hline Malaysia & 1991Q1-2003Q1 & IFS \\
\hline Mexico & 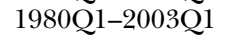 & OECD \\
\hline Peru & 1990Q1-2003Q1 & IFS \\
\hline Philippines & 1981Q1-2003Q1 & IFS \\
\hline Slovak Republic & 1993Q1-2003Q2 & OECD \\
\hline South Africa & 1980Q1-2003Q1 & IFS \\
\hline Thailand & 1993Q1-200301 & IFS \\
\hline Turkey & 1987Q1-2003Q2 & OECD \\
\hline \multicolumn{3}{|l|}{ Developed markets: } \\
\hline Australia & 1979Q1-2003Q2 & OECD \\
\hline Austria & 1988Q1-200302 & OECD \\
\hline Belgium & 1980Q1-2003Q2 & OECD \\
\hline Canada & 1981Q1-2003Q2 & OECD \\
\hline Denmark & 1988Q1-2003Q1 & OECD \\
\hline Finland & 1979Q4-2003Q2 & OECD \\
\hline Netherlands & 1979 Q4-2003Q2 & OECD \\
\hline New Zealand & 1987Q2-2003Q2 & OECD \\
\hline Norway & 1979Q4-200302 & OECD \\
\hline Portugal & 1988Q1-2001Q4 & $\mathrm{NP}$ \\
\hline Spain & 1980Q1-2003Q2 & OECD \\
\hline Sweden & 1980Q1-2003Q1 & IFS \\
\hline Switzerland & 1980Q1-2003Q2 & OECD \\
\hline
\end{tabular}

rate $) \times($ rate of activity of population over 12 years of age $) \times($ fraction of population over 12 years of age) $\times$ (total population). All series were obtained from the Mexican Government Statistical Database (through Datastream) with the exception of the total population series, which comes from the World Development Indicators. The employment series is extended back to 1987 using Neumeyer and Perri (2005). For Mexico, quarterly hours per worker in manufacturing is calculated from OECD data as (total hours in manufacturing)/(total employment in manufacturing). This ratio is then used to calculate total hours from total employment.

The capital stock series is calculated using the perpetual inventory method. The Penn World Tables report gross fixed capital formation starting in 1950. As in Bernanke and Gurkaynak (2002), we assume that capital and output grew at the same rate between 1950 and 1960. The initial capital stock for 1949 is then calculated as the ratio of investment in 1950 to the sum of the depreciation rate and annual average growth rate for 1950-60. We use a 10 percent annual depreciation rate. Starting with the capital stock in 1949 and updating using the data for investment from the Penn World Tables and the depreciation rate 
of 10 percent, we arrive at the capital stock for 1980. After 1980 we use the quarterly investment series from OECD.

The quarterly series for the Solow residual covers the period 1987Q1-2003Q2 for Mexico and 1981Q1-2003Q2 for Canada. The quarterly autocovariance functions depicted in figure 5 are estimated using the employment-based measures. To perform the random walk decomposition of figure 2, we use the longer, annual, series constructed by Bergoeing et al. (2002), which covers the period 1980-2000. This series uses hours as its measure of labor input. We extend Bergoeing et al.'s annual series to 2002 using the annual averages of our hoursbased residual. Similarly, figure 2 depicts our annualized hours-based series for Canada. In figure 1, we plot the two annualized hours-based series.

\section{References}

Aguiar, Mark, and Gita Gopinath. 2005. "Emerging Market Business Cycles: The Cycle Is the Trend." Manuscript, Univ. Rochester and Harvard Univ., Dept. Econ.

- 2006. "Defaultable Debt, Interest Rates and the Current Account." J. Internat. Econ. 69 (June): 64-83.

Aiyagari, S. Rao. 1994. "Uninsured Idiosyncratic Risk and Aggregate Saving." Q.J.E. 109 (August): 659-84.

Arellano, Cristina, and Enrique G. Mendoza. 2002. "Credit Frictions and 'Sudden Stops' in Small Open Economies: An Equilibrium Business Cycle Framework for Emerging Markets Crises." Working Paper no. w8880 (April), NBER, Cambridge, MA.

Backus, David K., Patrick J. Kehoe, and Finn E. Kydland. 1995. "International Business Cycles: Theory and Evidence." In Frontiers of Business Cycle Research, edited by Thomas F. Cooley. Princeton, NJ: Princeton Univ. Press.

Bergoeing, Raphael, Patrick J. Kehoe, Timothy J. Kehoe, and Raimundo Soto. 2002. "A Decade Lost and Found: Mexico and Chile in the 1980s." Rev. Econ. Dynamics 5 (January): 166-205.

Bernanke, Ben S., and Refet S. Gurkaynak. 2002. "Is Growth Exogenous? Taking Mankiw, Romer, and Weil Seriously." In NBER Macroeconomics Annual, vol. 16, edited by Ben S. Bernanke and Kenneth Rogoff. Cambridge, MA: MIT Press.

Beveridge, Stephen, and Charles R. Nelson. 1981. "A New Approach to Decomposition of Economic Time Series into Permanent and Transitory Components with Particular Attention to Measurement of the 'Business Cycle." J. Monetary Econ. 7 (March): 151-74.

Blundell, Richard, and Ian Preston. 1998. "Consumption Inequality and Income Uncertainty.” Q.J.E. 113 (May): 603-40.

Calvo, Guillermo A. 1986. "Temporary Stabilization: Predetermined Exchange Rates.” J.P.E. 94 (December): 1319-29.

Calvo, Guillermo A., and Carmen Reinhart. 2000. "When Capital Inflows Come to a Sudden Stop: Consequences and Policy Options." In Reforming the International Monetary and Financial System, edited by Peter B. Kenen and Alexander K. Swoboda. Washington, DC: Internat. Monetary Fund.

Campbell, John Y., and Angus Deaton. 1989. "Why Is Consumption So Smooth?" Rev. Econ. Studies 56 (July): 357-73.

Chari, V. V., Patrick J. Kehoe, and Ellen McGrattan. Forthcoming. "Business Cycle Accounting." Econometrica.

Cochrane, John H. 1988. "How Big Is the Random Walk in GNP?" J.P.E. 96 (October): 893-920. 
1994. "Permanent and Transitory Components of GNP and Stock Prices." Q.J.E. 109 (February): 241-65.

Correia, Isabel, Joao C. Neves, and Sergio Rebelo. 1995. "Business Cycles in a Small Open Economy." European Econ. Rev. 39 (June): 1089-1113.

Dornbusch, Rudiger, and Sebastian Edwards, eds. 1991. The Macroeconomics of Populism in Latin America. Chicago: Univ. Chicago Press (for NBER).

Gopinath, Gita. 2004. "Lending Booms, Sharp Reversals and Real Exchange Rate Dynamics." J. Internat. Econ. 62 (January): 1-23.

Greenwood, Jeremy, Zvi Hercowitz, and Gregory W. Huffman. 1988. "Investment, Capacity Utilization, and the Real Business Cycle." A.E.R. 78 (June): 402-17.

Hamilton, James D. 1994. Time Series Analysis. Princeton, NJ: Princeton Univ. Press.

Hansen, Lars Peter. 1982. "Large Sample Properties of Generalized Method of Moments Estimators." Econometrica 50 (July): 1029-54.

Mendoza, Enrique G. 1991. "Real Business Cycles in a Small Open Economy." A.E.R. 81 (September): 797-818.

Neumeyer, Pablo A., and Fabrizio Perri. 2005. "Business Cycles in Emerging Economies: The Role of Interest Rates.” J. Monetary Econ. 52 (March): 34580 .

Schmitt-Grohe, Stephanie, and Martin Uribe. 2003. "Closing Small Open Economy Models.” J. Internat. Econ. 61 (October): 163-85.

Standard and Poor's. 2000. Emerging Stock Markets Factbook, 2000. New York: McGraw-Hill.

Stock, James H., and Mark W. Watson. 2003. "Understanding Changes in International Business Cycle Dynamics.” Working Paper no. w9859 (July), NBER, Cambridge, MA. 